\title{
Avoiding Ambient Air and Light Induced Degradation in High-Efficiency Polymer Solar Cells by the Use of Hydrogen-Doped Zinc Oxide as Electron Extraction Material
}

\author{
Ermioni Polydorou, ${ }^{1,2}$ Elias Sakelis, ${ }^{1,3}$ Anastasia Soultati, ${ }^{1,4}$ Andreas Kaltzoglou, ${ }^{1}$ Theodoros A. \\ Papadopoulos, ${ }^{5}$ Joe Briscoe,${ }^{6}$ Dimitris Tsikritzis, ${ }^{7}$ Mihalis Fakis, ${ }^{2}$ Leonidas C. Palilis, ${ }^{2}$ Stella Kennou, ${ }^{7}$ \\ Panagiotis Argitis, ${ }^{1}$ Polycarpos Falaras, ${ }^{1}$ Dimitris Davazoglou, ${ }^{1}$ Maria Vasilopoulou ${ }^{1, *}$ \\ ${ }^{1}$ Institute of Nanoscience and Nanotechnology, National Center for Scientific Research Demokritos, 15310, Agia Paraskevi, Attiki, Greece \\ ${ }^{2}$ Department of Physics, University of Patras, 26504 Patras, Greece \\ ${ }^{3}$ University of Athens, Physics Department, Section of Solid State Physics, Panepistimioupolis, 15684 Zografos, Athens, Greece \\ ${ }^{4}$ Department of Chemical Engineering, National Technical University of Athens, 15780, Athens, Greece \\ ${ }^{5}$ Department of Natural Sciences, University of Chester, Thornton Science Park, CH2 4NU, Chester, U. K. \\ ${ }^{6}$ Materials Research Institute, School of Engineering and Materials Science, Queen Mary University of London, U. K. \\ ${ }^{7}$ Department of Chemical Engineering, University of Patras, 26500 Patras, Greece \\ *email:m.vasilopoulou@inn.demokritos.gr
}

Keywords: Zinc oxide, Hydrogen doping, Polymer solar cells, Passivation, Long-term stability, Photostability.

\begin{abstract}
Polymer solar cells have undergone rapid development in recent years. Their limited stability to environmental influence and during illumination, however, still remains a major stumbling block to the commercial application of this technology. Several attempts have been made to address the instability issue, mostly concentrated on the insertion of charge transport interlayers in the device stack. Although zinc oxide ( $\mathrm{ZnO})$ is one of the most common electron transport materials in those cells, the presence of defects at the surface and grain boundaries significantly affects the efficiency and stability of the working devices. To address these issues, we herein employ hydrogen-doping of the $\mathrm{ZnO}$ electron extraction material. It is found that devices based on photoactive layers composed of blends of poly(3-hexylthiophene) (P3HT) with electron acceptors possessing different energy levels, such as [6,6]-phenyl- $\mathrm{C}_{70}$ butyric acid methyl ester $\left(\mathrm{PC}_{70} \mathrm{BM}\right)$ or indene- $\mathrm{C}_{60}$ bisadduct $\left(\mathrm{IC}_{60} \mathrm{BA}\right)$ enhanced the photovoltaic performance considerably when using the hydrogen-doped $\mathrm{ZnO}$. In particular, it is observed that the maximum power conversion efficiency (PCE) reaches values of $4.62 \%$ and $6.65 \%$, respectively, which are much higher than those of the cells with the pristine $\mathrm{ZnO}(3.08 \%$ and $4.51 \%$ ). Most significantly, the degradation of non-encapsulated solar cells when exposed to ambient or under prolonged illumination is studied and it is found that devices based on un-doped $\mathrm{ZnO}$ showed poor environmental stability and significant photo-degradation while those using hydrogen-doped $\mathrm{ZnO}$ interlayers exhibited high long-term ambient stability and maintained nearly 80-90\% of their initial PCE values after 40 hours of 1.5 AM illumination. All mechanisms responsible for this enhanced device stability are elucidated and corresponding models are proposed. This work successfully addresses and tackles the device instability problem of polymer solar cells and the key findings pave the way for the upscaling of these and, perhaps, of related devices such as perovskite solar cells.
\end{abstract}

\section{Introduction}

Polymer solar cells (PSCs) offer a cost-effective path to harvesting the abundant renewable resource of solar energy [1-4]. To date, PSCs based on interpenetrating networks of low bandgap polymer donors and fullerene acceptors have exhibited power conversion efficiencies (PCEs) exceeding 10\% for single-junction [5], and $12 \%$ for tandem-junction PSCs consisting of stacks of individual cells with complementary absorption [6]. However, to further advance PSCs to photovoltaic applications, efficient devices exhibiting high environmental stability and photostability under constant illumination are required. Besides the design and synthesis of low-bandgap polymer materials with higher absorption efficiency and charge mobilities [7], interface modification using appropriate charge selective interlayers is essential for improving performance $[8,9]$. Zinc oxide $(\mathrm{ZnO})$ is a widely utilized n-type material implemented as electron transport interlayer in PSC devices where its inherent transparency, tunable electronic properties, non-toxicity and low cost can be combined to confer superior device properties [10-13]. In addition, $\mathrm{ZnO}$ exhibits the advantage of relatively ease thin-film preparation which may be achieved by a diverse range of solution-processing techniques thus being compatible with large area manufacturing [14-17]. However, defects such as oxygen vacancies $\left(\mathrm{V}_{\mathrm{O}}\right)$ and zinc interstitials $\left(\mathrm{Zn}_{\mathrm{i}}\right)$ are always present at surface and grain boundaries of $\mathrm{ZnO}$ and act as charge traps 
leading to high recombination rates of the photogenerated charges thus causing significant degradation on the solar cell performance [18-24]. Another well-known feature of $\mathrm{ZnO}$ defect states is their sensitivity to several adsorbates like oxygen species, which are always present in air-processed $\mathrm{ZnO}$ films and have a negative impact on the photostability of the resulting solar cell [25-27].

A number of endeavors have been directed to solve these issues, and the photovoltaic performance of PSCs using $\mathrm{ZnO}$ interlayers has significantly improved in recent years; an example is subjecting the devices to ultraviolet (UV) light exposure, the so-called "light-soaking" approach [28-31], which, however, may have a negative impact on the device lifetime. Also, employing self-assembled monolayers (SAMs), small molecules or high-molar-mass polymers such as poly(ethylene oxide) (PEO) and poly(ethylene glycol) (PEG) on top of $\mathrm{ZnO}$ layers can avoid direct contact with photoactive layers, and may also result in the passivation of surface defects [32-40]. However, most of these methods, while reducing the amount of surface defect states, do not passivate the defects present in the grain boundaries of the interlayer. Neither do they improve the intrinsic electrical properties of $\mathrm{ZnO}$ films, which are generally not of adequate conductivity as required for efficient electron transport and scale-up of the obtained efficiencies in PSC devices. The conductivity enhancement of the material has been observed under the presence of dopants which also passivate defect states and hamper the adsorption of oxygen. Doping of $\mathrm{ZnO}$ electron transport interlayers has been carried out with a variety of different elements, such as aluminum (Al) [41,42], indium (In) [43], cesium (Cs) [44], yttrium (Y) [45], and nitrogen (N) [46], predominantly to improve the conductivity, allowing for the use of thicker interlayers which may be produced in fast production techniques such as roll-to-roll processing. Development of doped charge transport interlayers has been identified to be of paramount importance in achieving highly efficient devices with adequate stability $[47,48]$. Doping with hydrogen $(\mathrm{H})$ is also expected to simultaneously passivate native defects and favorably affect the n-type conductivity of $\mathrm{ZnO}$; according to the research of Van der Walle, hydrogen forms multicenter bonds with neighboring atoms thus modifying the electronic structure of $\mathrm{ZnO}$ for a conductivity boost [49-51]. Recently, our group and others introduced the beneficial surface modification of $\mathrm{ZnO}$ by using a hydrogen plasma treatment for efficient inverted PSCs [52,53]. However, simple surface modification cannot afford solar cells with prolonged lifetime and photostabilities since defects present at grain boundaries may be detrimental for the device stability. Here we present an approach to simultaneously modify and thereby stabilize the $\mathrm{ZnO}$ surface and bulk via hydrogen doping achieved by a simple post-annealing step in hydrogen environment instead of air annealing. Doping of $\mathrm{ZnO}$ via hydrogen annealing has previously been shown to passivate defects and improve the electrical and optical properties of $\mathrm{ZnO}[49,54]$. However, the benefits of such doping have not yet been demonstrated in polymer solar cell technology. Here, inverted devices based on photoactive blends of poly(3-hexylthiophene) (P3HT) with either $[6,6]$-phenyl- $\mathrm{C}_{70}$ butyric acid methyl ester $\left(\mathrm{PC}_{70} \mathrm{BM}\right)$ or indene- $\mathrm{C}_{60}$ bisadduct ( $\left.\mathrm{IC}_{60} \mathrm{BA}\right)$ substantially enhance their photovoltaic performance reaching PCE values of $4.62 \%$ and $6.65 \%$, respectively, when using the hydrogen-doped $\mathrm{ZnO}$ interlayers, which are much higher than those of the reference cells with the un-doped $\mathrm{ZnO}$ (3.08\% and $4.51 \%$, respectively). Most significantly, while non-encapsulated devices based on pristine $\mathrm{ZnO}$ showed poor environmental stability and significant photo-degradation, those using hydrogen-doped $\mathrm{ZnO}$ interlayers exhibited high long-term ambient stability and photostability. In particular, they maintained nearly $80-90 \%$ of their initial PCE values after 40 hours of 1.5 AM illumination which represents one of the few cases where high efficiency polymer solar cells exhibit such remarkable photostability [55]. In order to explain in details the differences between devices using un-doped and hydrogen-doped $\mathrm{ZnO}$ materials, in addition to the analysis of ambipolar and unipolar devices, we use atomic force microscopy (AFM), scanning electron microscopy (SEM), X-ray and ultraviolet photoelectron spectroscopy (XPS and UPS respectively), Fourier Transform Infrared (FTIR) and UV/Vis absorption spectroscopy, steady-state and transient photoluminescence (PL) spectroscopy, X-ray diffraction (XRD) and contact angle measurements while also performing theoretical calculations.

\section{Results and discussion}

2.1 Performance and stability improvement in polymer solar cells with hydrogen-doped $\mathrm{ZnO}$ interlayers. The configuration of the inverted polymer solar cells using $\mathrm{ZnO}$ electron transport interlayer materials is illustrated in Fig. 1a, where the chemical structures of organic semiconductors used in this study are also shown. The cross-section scanning electron microscopy (SEM) image of the inverted device is also shown in Fig. 1a. ZnO films were prepared using a zinc acetate precursor as described in details in the experimental section and then annealed either in air or in hydrogen environment for 20 minutes at temperatures ranging between 100 and $350^{\circ} \mathrm{C}$. Fig. S1 (shown in Supporting Information) demonstrates the current density- 

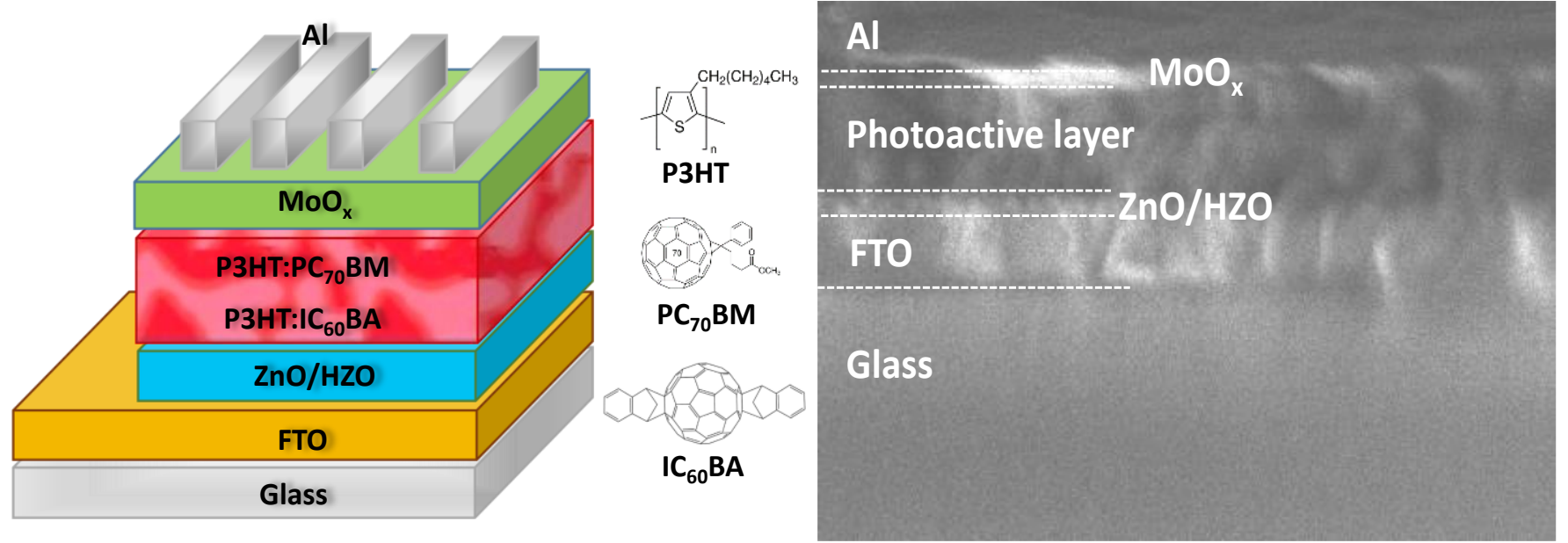

(a)
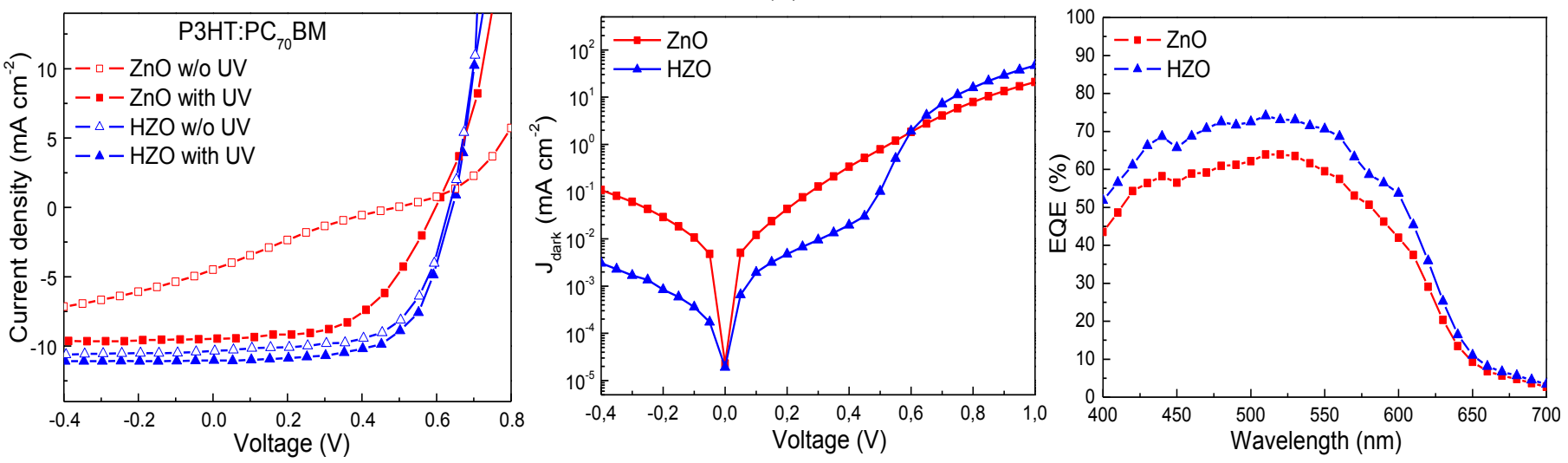

(b)
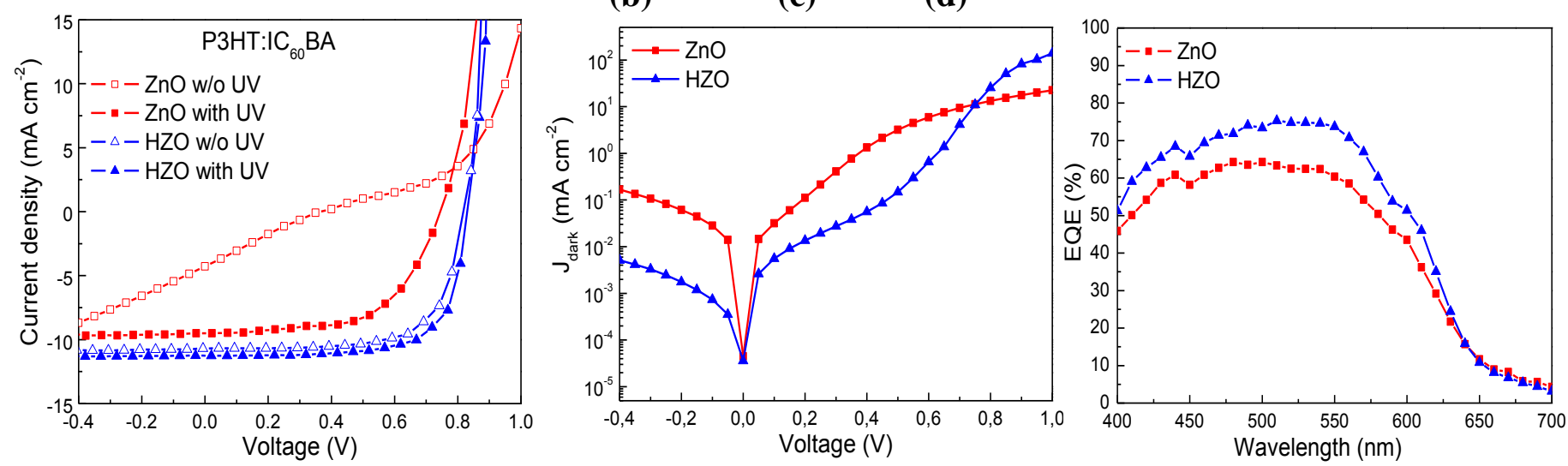

(e)

(g)

Figure 1 (a) The inverted device architecture and the chemical structures of the organic semiconductors used in this study. SEM image for the cross-section of the inverted polymer solar cell architecture used here: glass/FTO/ZnO or $\mathrm{HZO} /$ photoactive layer/ $\mathrm{MoO}_{\mathrm{x}} / \mathrm{Al}$. (b) Current density versus voltage $(\mathrm{J}-\mathrm{V})$ characteristics of the P3HT:PC $70 \mathrm{BM}$-based devices using $\mathrm{ZnO} / \mathrm{HZO}$ as electron transport interlayers upon 1.5 $\mathrm{AM}$ illumination without $\mathrm{UV}$ spectral components (blocking filter) and with full 1.5 AM spectrum. (c) The dark J-V curves and (d) EQE measurements of the P3HT:PC ${ }_{70} \mathrm{BM}$-based diodes. (e) J-V characteristics of the P3HT:IC ${ }_{60} \mathrm{BA}$ based devices using $\mathrm{ZnO} / \mathrm{HZO}$ interlayers upon 1.5 AM illumination without UV spectral components (blocking filter) and with full 1.5 AM spectrum. (f) The dark J-V curves and (g) EQE measurements of the P3HT:IC ${ }_{60} \mathrm{BA}$-based diodes.

voltage $(\mathrm{J}-\mathrm{V})$ characteristics of devices based on $\mathrm{P} 3 \mathrm{HT}: \mathrm{PC}_{70} \mathrm{BM}$ blends measured under 1.5 AM illumination in air. It is shown that devices using the air-annealed $\mathrm{ZnO}$ (termed hereafter as $\mathrm{ZnO}$ ) require an annealing temperature above $200{ }^{\circ} \mathrm{C}$ with the best efficiencies to be achieved for annealing at $250-300{ }^{\circ} \mathrm{C}$, which is due to the high decomposition temperature of zinc acetate [23]. On the contrary, devices using the hydrogenannealed $\mathrm{ZnO}$ interlayer (termed hereafter as $\mathrm{HZO}$ ) always exhibit better performance, with high efficiencies achieved even at $150{ }^{\circ} \mathrm{C}$. This indicates that our methodology for improving performance of PSCs via hydrogen-doping (annealing) of $\mathrm{ZnO}$ could also find application in flexible devices where lower annealing temperatures are required. However, given that we obtained better stabilities in P3HT:PC $70 \mathrm{BM}$-based devices 
having their $\mathrm{ZnO}$ annealed above $200{ }^{\circ} \mathrm{C}$, in the following experiments we set the temperature (of both air and hydrogen annealing) at $300^{\circ} \mathrm{C}$. Figs $1 \mathrm{~b}$ and 1 e represent the $\mathrm{J}-\mathrm{V}$ characteristics under full $1.5 \mathrm{AM}$ simulated solar illumination (with the UV component) of fresh devices using photoactive blends based on P3HT:PC $70 \mathrm{BM}$ and $\mathrm{P} 3 \mathrm{HT}: \mathrm{IC}_{60} \mathrm{BA}$ with $\mathrm{ZnO}$ and $\mathrm{HZO}$ electron transport layers, respectively. The corresponding electrical output parameters of those devices are summarized in Table 1 . The dark $\mathrm{J}-\mathrm{V}$ measurements are also shown in Figs $1 \mathrm{c}$ and $1 \mathrm{f}$ while the external quantum efficiency (EQE) characteristics of the same devices are presented in Figs $1 \mathrm{~d}$ and 1g. For the P3HT:PC ${ }_{70} \mathrm{BM}$ based device with the HZO layer a high PCE of $4.62 \%$ is obtained representing a nearly $50 \%$ improvement in comparison to the PCE value of $3.08 \%$ obtained in the device using the air-annealed $\mathrm{ZnO}$ interlayer. Similarly, the reference P3HT:IC ${ }_{60} \mathrm{BA}$ based device with $\mathrm{ZnO}$ exhibits an average PCE of $4.51 \%$, while the $\mathrm{HZO}$ device showed a $47 \%$ higher PCE reaching the value of $6.65 \%$. From the photovoltaic parameters presented in Table 1 becomes evident that $\mathrm{HZO}$ interlayer leads to a simultaneous improvement in the open-circuit voltage $\left(\mathrm{V}_{\mathrm{oc}}\right)$, short-circuit current $\left(\mathrm{J}_{\mathrm{sc}}\right)$ and fill factor $(\mathrm{FF})$. Next, we also measured the $\mathrm{J}-\mathrm{V}$ curves for similar $\mathrm{ZnO} / \mathrm{HZO}$ based PSCs under illumination without the UV light content which was excluded through the application of a UV long-pass filter with a cut-off at $400 \mathrm{~nm}$ (Figs $1 \mathrm{~b}$ and 1e). It is observed that the devices using $\mathrm{ZnO}$ interlayers yielded an inflection around the $\mathrm{V}_{\text {oc }}$ point when they were not subjected to UV activation. This suggests that the UV activation is necessary for the induction of photoconductivity and oxygen desorption in the un-doped $\mathrm{ZnO}$ layer and the elimination of the electron extraction barrier as also reported by other groups and may explain the lower photovoltaic performance of our reference devices with $\mathrm{ZnO}$ (which were not UV activated) as compared to other works $[25,55,56]$. On the contrary, there was negligible change in the performance of devices using HZO interlayer under illumination without the UV component. Those devices exhibit no inflection in their $\mathrm{J}-\mathrm{V}$ curve prior to $\mathrm{UV}$ exposure suggesting that the $\mathrm{HZO}$ interlayer benefited from an improved conductivity due to hydrogen-doping and a reduced electron extraction barrier due to lowering of its workfunction as is also reported for Al-doped $\mathrm{ZnO}$ layers [25]. Note that we used non-UV activated $\mathrm{ZnO}$ reference devices in order to make a straight comparison with the HZO based ones. Moreover, we also applied $\mathrm{ZnO}$ and $\mathrm{HZO}$ interlayers in devices using one of the most efficient donor:acceptor combination the PTB7:PC 70 BM mixture. Our preliminary results shown in Fig. S2 evidenced the beneficial effect of hydrogendoping of the interlayers since the device using HZO layer delivered a high PCE of $7.67 \%$ which represents a $44 \%$ improvement in comparison to that of the reference cell with the un-doped $\mathrm{ZnO}(5.30 \%)$. Note that in the case of PTB7:PC $70 \mathrm{BM}$-based devices the annealing temperature of both $\mathrm{ZnO}$ and $\mathrm{HZO}$ layers was set at $200{ }^{\circ} \mathrm{C}$ where we obtained the best device performance. However, these are preliminary results and further investigation is carried out.

In addition, the dark $\mathrm{J}-\mathrm{V}$ characteristics (shown here in semi logarithmic scale) are improved greatly in the case of $\mathrm{HZO}$ cells, compared to $\mathrm{ZnO}$ ones. The distinctly different regions of the $\mathrm{J}-\mathrm{V}$ curves for diode operation in the dark are seen only in the case of HZO. Importantly, the reverse saturation current density decreased significantly whereas the turn-on (onset) voltage of the corresponding diodes increased. Furthermore, a distinct exponential current rise is seen above the turn-on region with an increase of the injected current noted and a clear shift of the J-V curve. These results suggest that hydrogen-doping in HZO reduces reverse leakage and shunt current while it also facilitates electron extraction probably due to an increase of the built-in field and/or due to enhanced (n-type) conductivity/mobility. As a result, a highly improved diode rectification ratio is observed in HZO-modified interface based solar cells while the increased built-in field may also promote the extraction of photogenerated carriers. Both reduction of the reverse saturation current and increase of the turn-on voltage contribute to the increase of the $\mathrm{V}_{\mathrm{oc}}$ of the HZO solar cells. If $\mathrm{V}_{\mathrm{oc}}$ is expressed according to the Shockley equation:

$$
V_{o c}=\frac{n K_{B} T}{q_{e}} \ln \left[\frac{J_{p h}}{J_{o}}+1\right]
$$

and taking into consideration that $J_{0}$ is given by the expression:

$$
J_{o}=J_{s o} \exp \left[\frac{-\left(H O M O_{D}-L U M O_{A}\right)}{2 n K_{B} T}\right]
$$




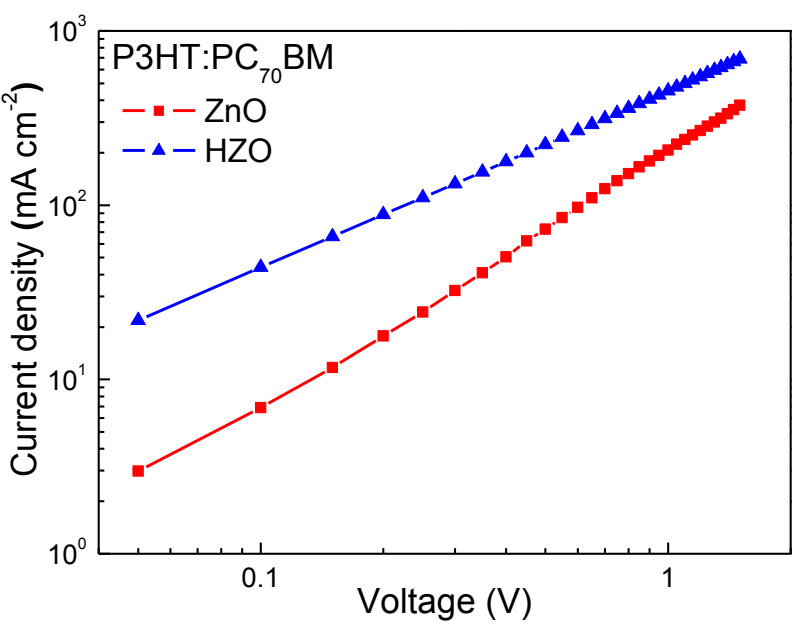

(a)

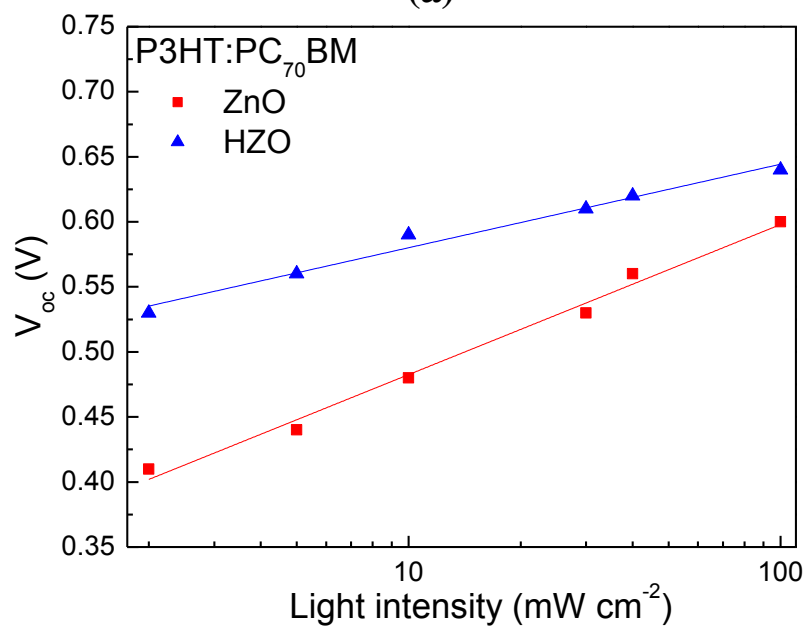

(c)

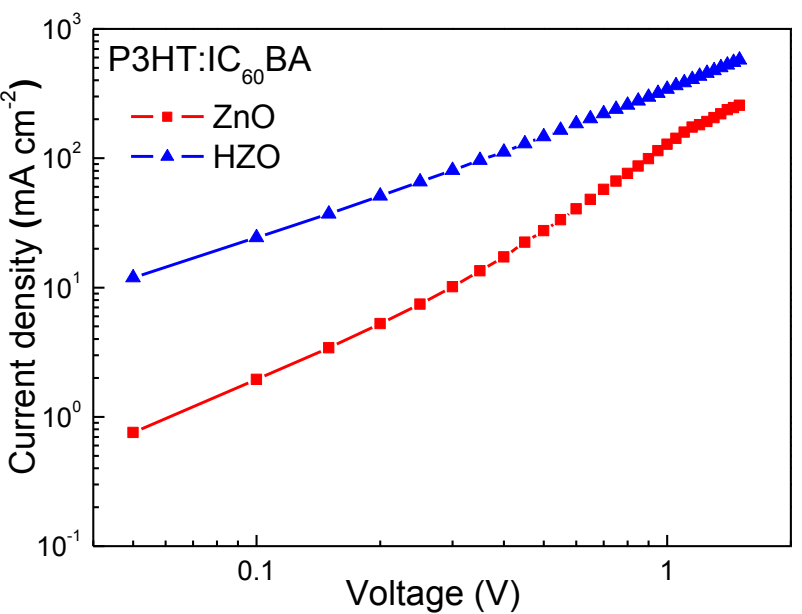

(b)

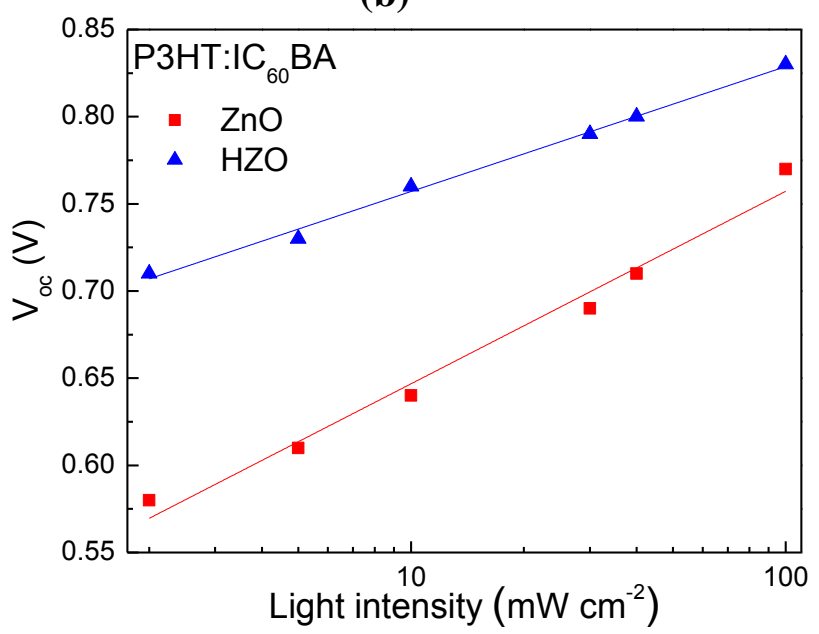

(d)

Figure $2 \mathrm{~J}-\mathrm{V}$ curves in log-log plot obtained in electron-only (a) P3HT: $\mathrm{PC}_{70} \mathrm{BM}$-based and (b) P3HT:IC ${ }_{60} \mathrm{BA}$-based devices with $\mathrm{ZnO} / \mathrm{HZO}$ interlayers, measured in the dark. Dependence of $\mathrm{V}_{\mathrm{oc}}$ on light intensity for (c) P3HT:PC $70 \mathrm{BM}$ based and (d) P3HT:IC ${ }_{60} \mathrm{BA}$-based devices with $\mathrm{ZnO} / \mathrm{HZO}$ interlayers.

then

$$
V_{o c}=\frac{n K_{B} T}{q_{e}} \ln \left[\frac{J_{s c}}{J_{o}}\right]+\frac{H O M O_{D}-L U M O_{A}}{2 q_{e}}
$$

where $n$ is the ideality factor, $K_{B}$ is the Boltzmann constant, $T$ is the temperature, $q_{e}$ is the electron charge, $\mathrm{HOMO}_{\mathrm{D}}$ is the HOMO of the donor and $\mathrm{LUMO}_{\mathrm{A}}$ is the LUMO of the acceptor, $J_{s c}$ is the short-circuit photocurrent density and $J_{o}$ is the reverse saturation current density. According to (3), a strong decrease of the dark reverse saturation current will result in significant increase of the $\mathrm{V}_{\mathrm{oc}}$ as in the case of $\mathrm{HZO}$ solar cells. In addition, the device with the HZO interlayer exhibits significantly reduced series and larger shunt resistances (Table 1) verifying the overall higher quality of the corresponding diodes and explaining the enhanced short-circuit current $\left(J_{\mathrm{sc}}\right)$ and fill factor $(\mathrm{FF})$ obtained in the device with the HZO interlayer. The large improvement in $J_{\mathrm{sc}}$ is confirmed by the external quantum efficiency (EQE) measurements where HZO cells exhibit an enhanced efficiency throughout the full spectral range. Note that, by integrating the product of the incident photon flux density with the EQE values over the 350 to $750 \mathrm{~nm}$ wavelength regime predicted short-circuit photocurrents, $J_{\mathrm{sc}}^{\mathrm{EQE}}$, attained by the cells can be calculated (Table 1 ). The close proximity of the $J_{\mathrm{sc}}$ and $J_{\mathrm{sc}}^{\mathrm{EQE}}$ is an indication for low bimolecular recombination in these devices.

2.2 Additional devices characterization, nanomorphology and photophysical properties of photoactive layers on zinc oxides. The decrease in series resistances of $\mathrm{HZO}$ devices indicates that electrons are extracted more efficiently as verified from the $\mathrm{J}-\mathrm{V}$ characteristics taken in electron-only devices with a structure $\mathrm{FTO} / \mathrm{ZnO}$ or $\mathrm{HZO} / \mathrm{P} 3 \mathrm{HT}: \mathrm{PC}_{70} \mathrm{BM} / \mathrm{Al}$ (Fig. 2a) or FTO/ZnO or HZO/P3HT:IC $60 \mathrm{BA} / \mathrm{Al}$ (Fig. 2b) where the $\mathrm{MoO}_{\mathrm{x}} / \mathrm{Al}$ hole selective contact is replaced with simple $\mathrm{Al}$, which is able to inject electrons into the 


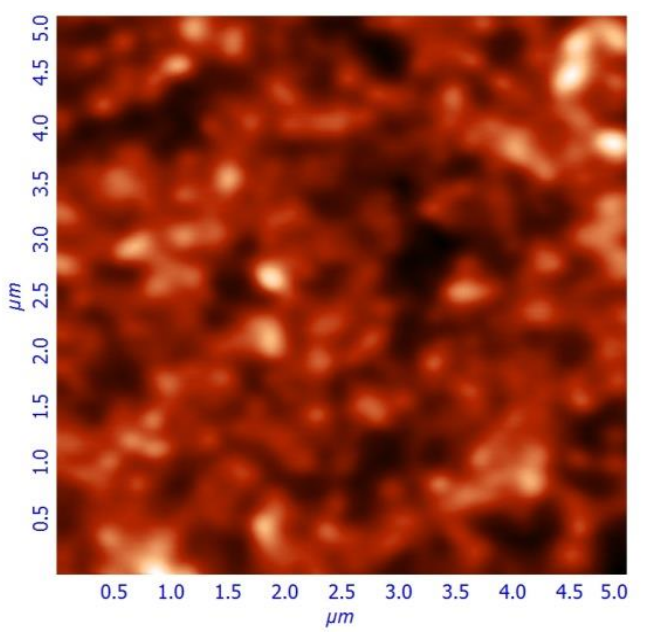

(a)

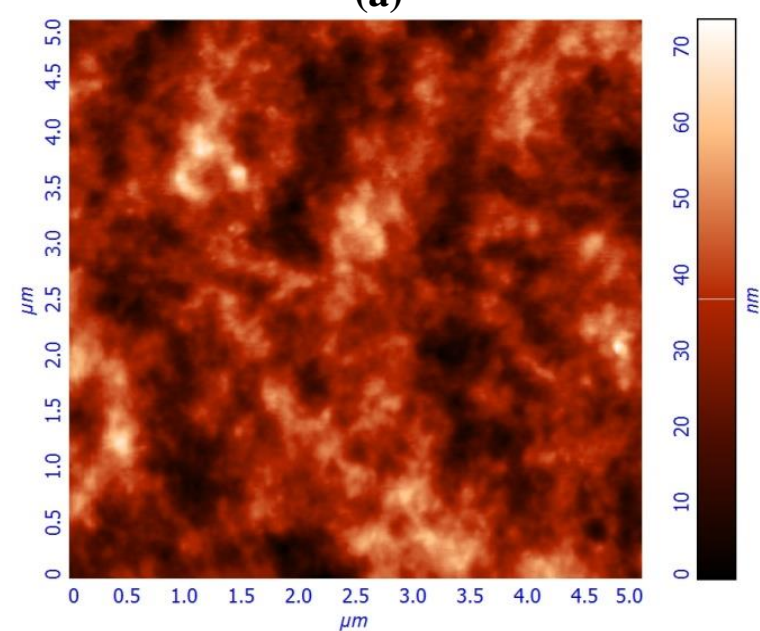

(c)

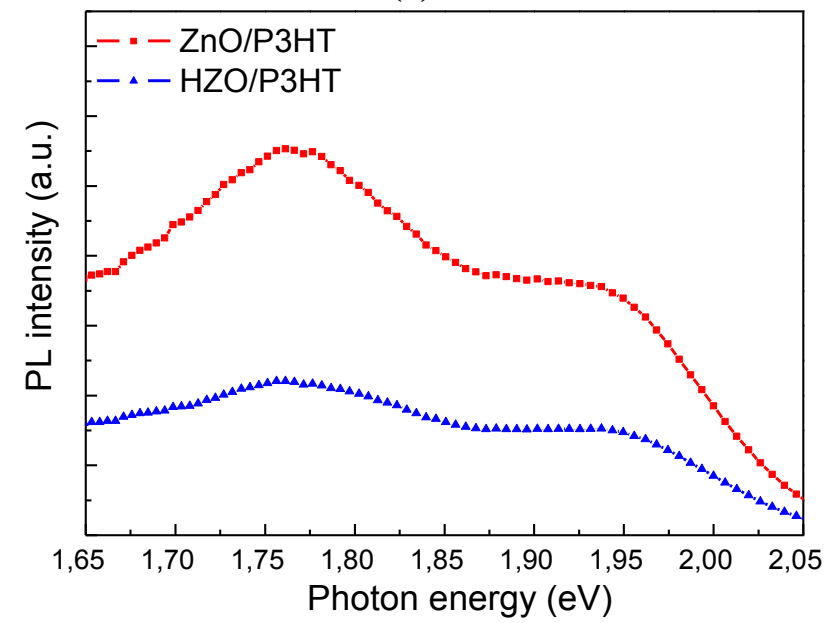

(e)

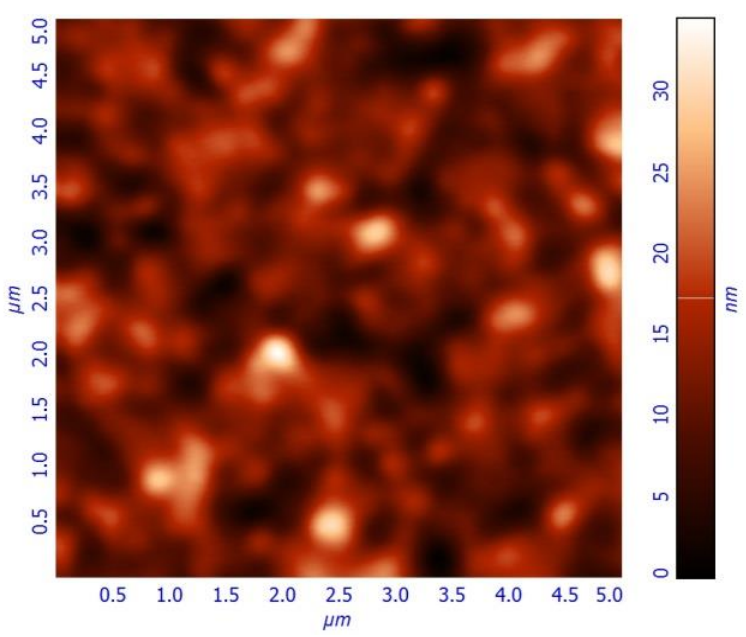

(b)

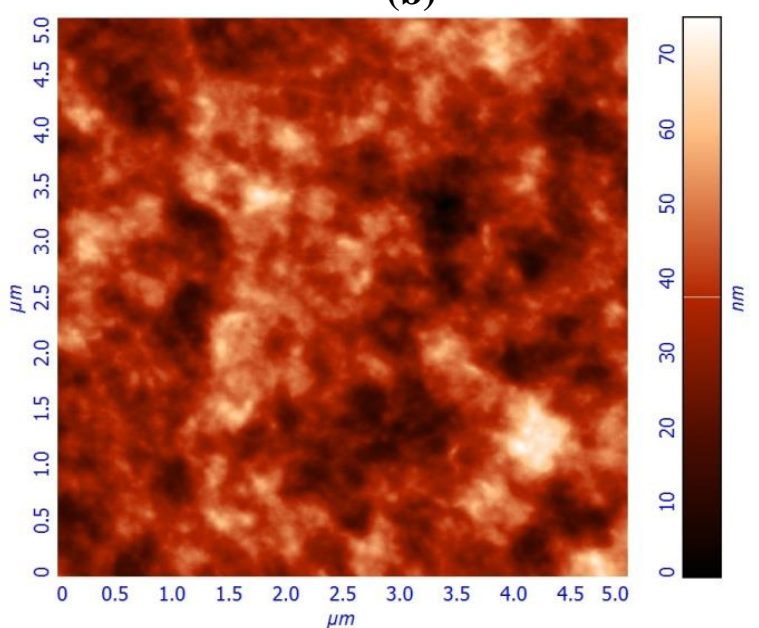

(d)

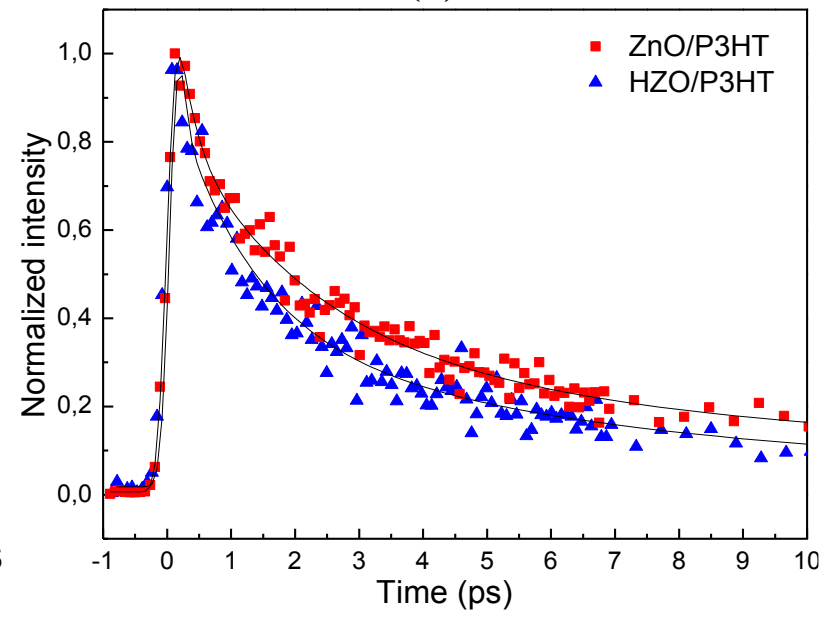

(f)

Figure $32 \mathrm{D}$ atomic force microscopy (AFM) topographies $(5 \times 5 \mu \mathrm{m})$ of (a), (b) P3HT:PC $70 \mathrm{BM} 120 \mathrm{~nm}$ thick films, and of (c), (d) P3HT:IC ${ }_{60} \mathrm{BA} 200 \mathrm{~nm}$ thick films deposited on $\mathrm{ZnO}$ (a and c) and $\mathrm{HZO}$ (b and d) films. (e) Steady-state $\mathrm{PL}$ spectra of P3HT on ZnO/HZO layers and (f) Transient PL dynamics of P3HT thin film (10 nm) on different $\mathrm{ZnO}$ layers detected at $670 \mathrm{~nm}$.

lowest unoccupied molecular orbital (LUMO) of fullerene acceptors. It is evident that both devices based on $\mathrm{ZnO}$ show small current densities in the forward direction while a substantial increase in electron current is found in the HZO-based devices. This clearly corroborates the enhancement of selectivity of the HZO/organic interfaces while the increase in the shunt resistance (Table 1) also suggests that there is less interfacial recombination in the $\mathrm{HZO}$ devices. Further evidence for multiple operational recombination channels in the complete solar cell devices based on P3HT donor and different acceptors comes from steady-state J-V measurements where we monitor the variation of $\mathrm{V}_{\mathrm{oc}}$ of P3HT:PC ${ }_{70} \mathrm{BM}$ and P3HT:IC $60 \mathrm{BA}$-based devices under different light intensities (Figs $2 \mathrm{c}$ and 2d). We find that both kinds of P3HT-based devices exhibit slopes 
of $\mathrm{V}_{\mathrm{oc}}$ versus natural logarithmic of the light intensity larger than KT/q $(1.91 \mathrm{KT} / \mathrm{q}$ and $1.84 \mathrm{KT} / \mathrm{q}$, respectively) indicating a strong dependence on light intensity when using the $\mathrm{ZnO}$ interlayers, which can be assigned to significant surface recombination at $\mathrm{ZnO}$ /organic interfaces. In particular, these high slopes seem to imply an increased number of trap states and a, concomitant, large increase in the number of ShockleyRead-Hall (SRH) (monomolecular) or trap assisted recombination processes in the reference cells which is ascribed to an enhanced rate of surface recombination and can be associated with the low selectivity of the cathode contact as surface trap defects dominate recombination [57]. On the contrary, the slopes in the HZO based devices are significantly lower $\left(1.09\right.$ and $1.18 \mathrm{KT} / \mathrm{q}$ for the P3HT:PC ${ }_{70} \mathrm{BM}$ and P3HT:IC $60 \mathrm{BA}-\mathrm{based}$ devices, respectively) indicating a slower surface recombination rate and enhancement of selectivity of the cathode contact approaching conditions where bimolecular (e.g. Langevin) recombination dominates. Note that we also verified a similar trend in the slope changes of $\mathrm{V}_{\mathrm{oc}}$ versus light illumination for the more efficient active system (PTB7:PC 70 BM, Fig. S3) which verifies that changes in the slope can be attributed to different recombination rates at the cathode contact of the devices.

Table 1 Photovoltaic parameters of fresh solar cells having the configuration glass substrate/FTO/ZnO or HZO interlayer /photoactive layer/ $\mathrm{MoO}_{x} / \mathrm{Al}$ (mean values and standard deviations were extracted from a batch of 36 devices).

\begin{tabular}{|c|c|c|c|c|c|c|}
\hline $\begin{array}{c}\mathbf{J}_{\mathrm{sc}} \\
\left(\mathbf{m A} / \mathbf{c m}^{2}\right)\end{array}$ & $\begin{array}{l}\text { Voc }_{\text {oc }} \\
\text { (V) }\end{array}$ & FF & $\begin{array}{c}\text { PCE } \\
(\%)\end{array}$ & $\begin{array}{c}\mathbf{J}_{\mathbf{s c}} \mathbf{E Q E} \\
\left(\mathbf{m A} / \mathbf{c m}^{2}\right)\end{array}$ & $\begin{array}{c}R_{\mathrm{s}} \\
\left(\Omega \mathrm{cm}^{2}\right)\end{array}$ & $\begin{array}{c}R_{\text {sh }} \\
\left(\Omega \mathrm{cm}^{2}\right)\end{array}$ \\
\hline
\end{tabular}

P3HT:PC $70 B M$

\begin{tabular}{cccccccc}
\hline ZnO & $9.5( \pm 0.15)$ & $0.60( \pm 0.01)$ & $0.54( \pm 0.02)$ & 3.08 & 9.6 & 6.1 & 2100 \\
\hline HZO & $11.1( \pm 0.10)$ & $0.64( \pm 0.01)$ & $0.65( \pm 0.01)$ & 4.62 & 11.2 & 4.8 & 7900 \\
\hline
\end{tabular}

\section{P3HT:IC60BA}

\begin{tabular}{cccccccc}
\hline ZnO & $9.6( \pm 0.20)$ & $0.77( \pm 0.01)$ & $0.61( \pm 0.02)$ & 4.51 & 9.7 & 6.3 & 2605 \\
\hline HZO & $11.3( \pm 0.20)$ & $0.83( \pm 0.01)$ & $0.71( \pm 0.02)$ & 6.65 & 11.3 & 3.3 & 5650 \\
\hline
\end{tabular}

Because HZO layer was found to exhibit larger and more uniform distribution in topographic grains than $\mathrm{ZnO}$ (Fig. S4) as well as different surface energy (as indicated from contact angle measurements shown in Fig. S5), we next studied the differences in surface nanomorphology of the photoactive blends deposited on different $\mathrm{ZnO}$ substrates. The AFM topography images are shown in Figs 3a-d. It is observed that the distribution of donor and acceptors and their interpenetrating networks are not very different when deposited on different zinc oxide materials. However, a small reduction in the RMS roughness of the blends deposited on $\mathrm{HZO}$ layer is observed (4.6 nm for P3HT: $\mathrm{PC}_{70} \mathrm{BM}$ and 9.9 for P3HT:IC ${ }_{60} \mathrm{BA}$ ) when compared with blends deposited on $\mathrm{ZnO}(5.5 \mathrm{~nm}$ and $10.6 \mathrm{~nm}$, respectively). This indicates that the film formation and physical contact at the $\mathrm{HZO}$ / photoactive layer interface is more uniform and should lead to a more uniform electrical contact as indicated from the reduced series resistance and increased shunt resistances of HZO solar cells (Table 1). Note that a small reduction in the RMS roughness was also confirmed for $10 \mathrm{~nm}$ thin P3HT:PC $70 \mathrm{BM}$ and P3HT:IC ${ }_{60} \mathrm{BA}$ films deposited on HZO layers (Fig. S6) which indicates that hydrogen present on zinc oxide surface may improve photoactive blend nanomorphology, as previously reported by our group [58]. However, the improvement is not sufficient in order to explain the large enhancement in performance of the devices using HZO material.

Hydrogen-doping induced passivation of zinc oxide is the most prevalent hypothesis and was further probed by measuring the photophysical properties of P3HT films on $\mathrm{ZnO}$ and $\mathrm{HZO}$ layers. Steady state photoluminescence (PL) measurements on thin P3HT ( 10 nm) films deposited on ZnO and HZO layers are shown in Fig. 3e. Two emission peaks are observed at $1.95 \mathrm{eV}$ and $1.75 \mathrm{eV}$ corresponding to the $0-0$ transition and the 0-1 and 0-2 sidebands. An overall reduction of PL intensity is observed for P3HT deposited on HZO layer, showing increased ability of electron transfer from the photoactive layer to HZO interlayer. This is also confirmed by using transient spectroscopy to observe the excited state dynamics. The transient measurements were performed using the fs up-conversion technique upon excitation at $400 \mathrm{~nm}$ and detection at $670 \mathrm{~nm}$ (Fig. 3f). Fitting of the PL decays was made through multi-exponential functions and the results are summarized in 
Table 2. When P3HT is deposited on $\mathrm{ZnO}$ layer the average time-constant is calculated as $3.90 \mathrm{ps}$, while the $\mathrm{HZO}$ layer accelerates the electron decay process, with observed time constant of $1.78 \mathrm{ps}$. Overall, the steady state and transient PL measurements described here provide significant evidence that HZO layers cause enhanced exciton dissociation at the cathode interface which is considered a key challenge in improving the performance of polymer solar cells that equally affect the active layer. Musselman et al. proposes that the surface of the oxide, which is directly adjacent to the P3HT, critically influences charge transfer from the P3HT, and that the slower decay rates obtained with the un-doped $\mathrm{ZnO}$ surfaces follow from a larger density of trapped electrons on chemisorbed negatively charged oxygen molecules at the surface, which inhibit exciton dissociation and charge transfer from the P3HT to the oxide [46].

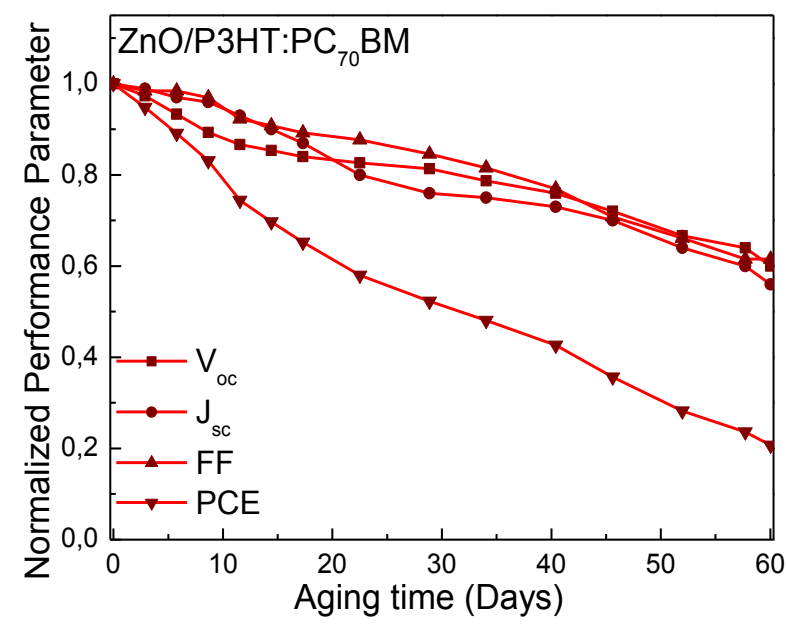

(a)

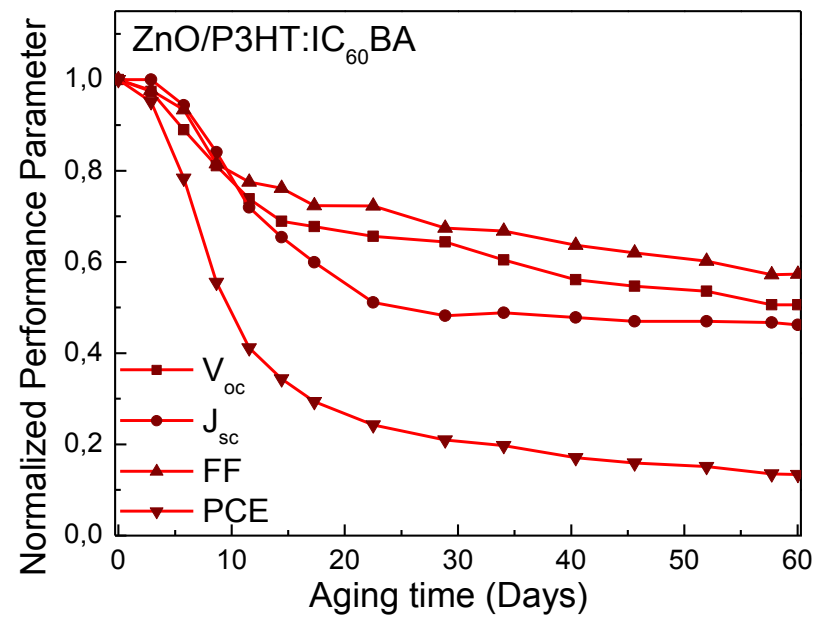

(c)

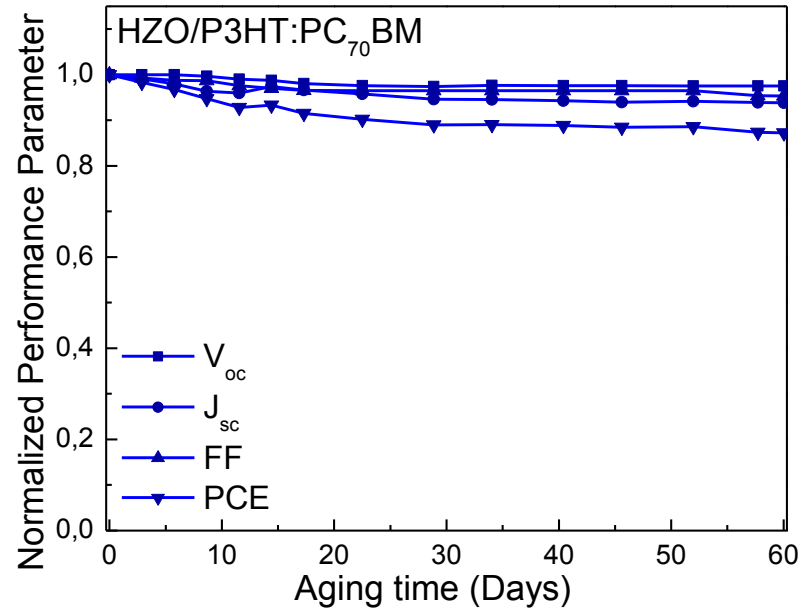

(b)

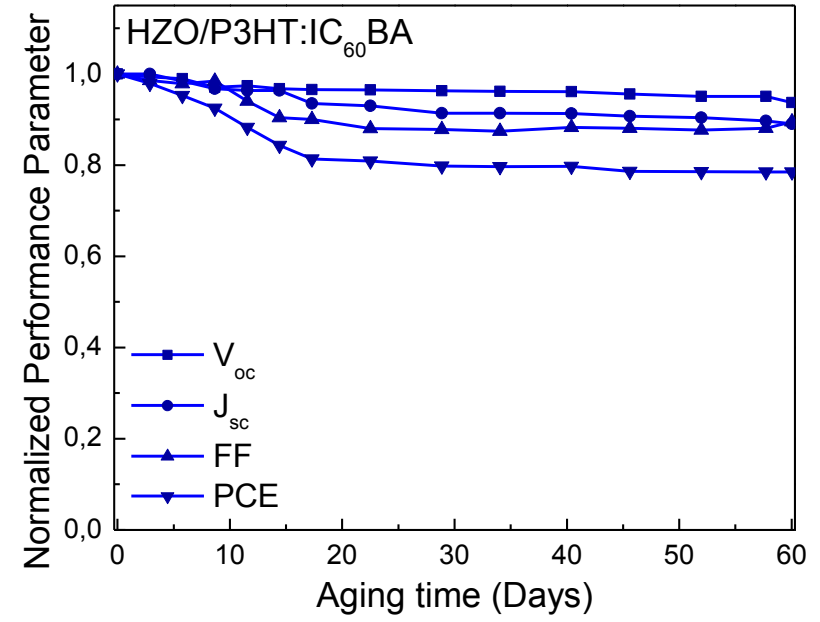

(d)

Figure 4 Stability measurements in ambient air: Variation of PCE, $\mathrm{J}_{\mathrm{sc}}, \mathrm{V}_{\mathrm{oc}}$ and $\mathrm{FF}$ over a period of 60 days for $\mathrm{P} 3 \mathrm{HT}$ : $\mathrm{PC}_{70} \mathrm{BM}$-based devices using (a) $\mathrm{ZnO}$ and (b) $\mathrm{HZO}$ interlayers and for P3HT:IC 60 BA-based devices using (c) $\mathrm{ZnO}$ and (d) $\mathrm{HZO}$ interlayers.

Table 2 Fitting parameters, obtained by means of a three-exponential function, of the P3HT films on $\mathrm{ZnO}$ substrates with different treatment. Excitation wavelength: $400 \mathrm{~nm}$. Detection wavelength: $670 \mathrm{~nm}$.

\begin{tabular}{lccccccc}
\hline Sample & $\mathbf{A}_{1}$ & $\begin{array}{l}\mathbf{t}_{1} \\
(\mathbf{p s})\end{array}$ & $\mathbf{A}_{2}$ & $\begin{array}{c}\mathbf{t}_{2} \\
(\mathbf{p s})\end{array}$ & $\mathbf{A 3}_{3}$ & $\begin{array}{c}\mathbf{t}_{3} \\
(\mathbf{p s})\end{array}$ & $\begin{array}{c}\langle\boldsymbol{t}\rangle \\
(\mathbf{p s})\end{array}$ \\
\hline ZnO/P3HT & 0.36 & 0.24 & 0.44 & 2.2 & 0.20 & 14 & 3.90 \\
\hline HZO/P3HT & 0.47 & 0.10 & 0.34 & 1.2 & 0.19 & 7 & 1.78 \\
\hline
\end{tabular}


2.3 High stability of polymer solar cells with HZO interlayers. In addition to the significant efficiency enhancement, the ambient stability of non-encapsulated devices is also substantially improved when using the HZO layer as shown in Fig. 4 where the variation over aging time of PCE, $\mathrm{J}_{\mathrm{sc}}, \mathrm{V}_{\text {oc }}$ and $\mathrm{FF}$ for P3HT:PC $70 \mathrm{BM}$ and P3HT:IC ${ }_{60} \mathrm{BA}$ based devices using $\mathrm{ZnO}$ (Figs $4 \mathrm{a}$ and 4c, respectively) or $\mathrm{HZO}$ (Figs $4 \mathrm{~b}$ and $4 \mathrm{~d}$, respectively) interlayers, is shown. It is evident that the operational characteristics of devices using $\mathrm{HZO}$ interlayers exhibited high stability preserving $87 \%$ of their original PCE values for the P3HT:PC 70 BM device and $80 \%$ for the P3HT:IC $60 \mathrm{BA}$ after being stored in ambient conditions for 60 days. In contrast, the PCE of P3HT:PC ${ }_{70} \mathrm{BM}$ and P3HT:IC 60 BA devices using air-annealed $\mathrm{ZnO}$ interlayers degraded to $20 \%$ and $14 \%$ of their original values, respectively, when stored under the same conditions. This result proves that hydrogen doping of $\mathrm{ZnO}$ can protect the photoactive layer from degradation in air and improve the long-term stability of devices effectively.

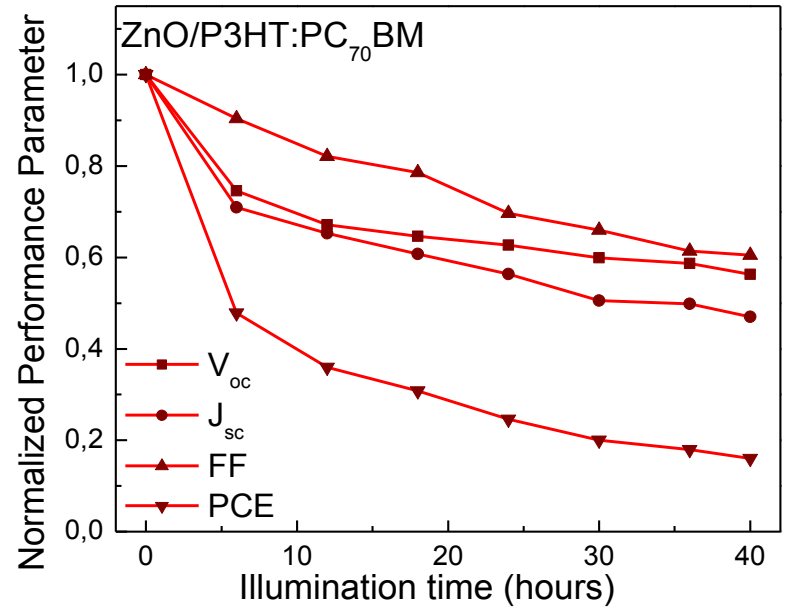

(a)

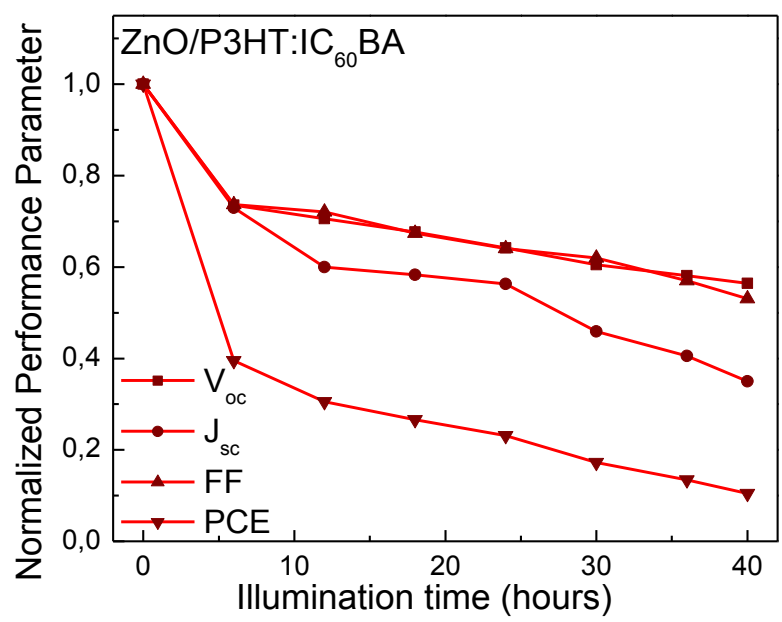

(c)

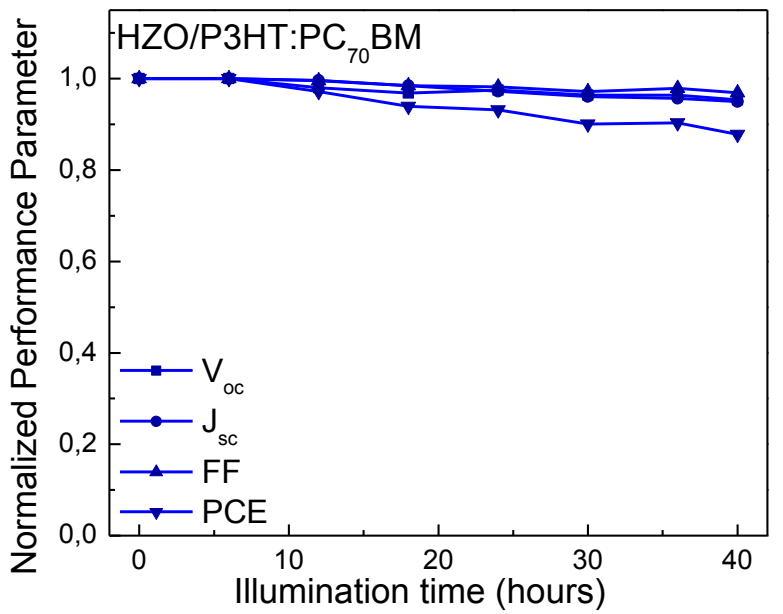

(b)

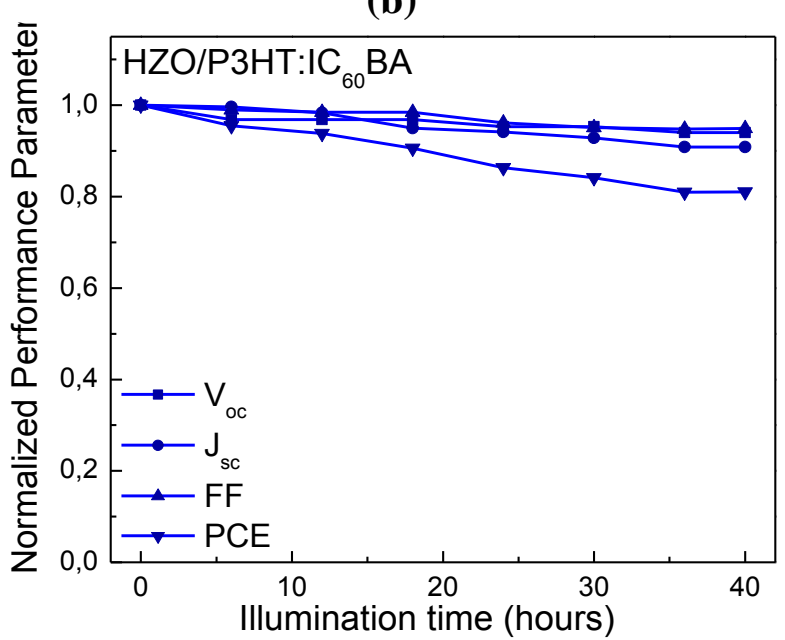

(d)

Figure 5 Photostability measurements: Variation of PCE, $\mathrm{J}_{\mathrm{sc}}, \mathrm{V}_{\mathrm{oc}}$ and $\mathrm{FF}$ of degraded under AM1.5G simulated sunlight for $40 \mathrm{~h}$ solar cells based on $\mathrm{P} 3 \mathrm{HT}: \mathrm{PC}_{70} \mathrm{BM}$ photoactive blend using (a) $\mathrm{ZnO}$ and (b) $\mathrm{HZO}$ interlayers and on P3HT:IC ${ }_{60} \mathrm{BA}$ photoactive blend using (c) $\mathrm{ZnO}$ and (d) $\mathrm{HZO}$ interlayers.

Photostability of polymer solar cells also represents a key requirement for the commercialization of this technology. We therefore investigated the degradation of our devices using $\mathrm{ZnO}$ or $\mathrm{HZO}$ interlayers under constant AM 1.5G illumination in ambient air [59]. As shown in Figs 5a and 5c, after 40 hours of illumination the PCE of P3HT:PC $70 \mathrm{BM}$ and P3HT:IC 60 BA devices decreased to $16 \%$ and $11 \%$ of their original values, respectively, when using the $\mathrm{ZnO}$ interlayer, while in the HZO-based devices they maintained $88 \%$ and $81 \%$ of their values (Figs 5b and 5d). Since the solar cells differ only on the nature of their electron transport interlayers, the differences in their overall photostability can be ascribed to degradation process involving the interlayer. It is reasonable to assume that oxygen adsorption on the $\mathrm{ZnO}$ surface during air processing causes the degradation of $\mathrm{J}_{\mathrm{sc}}, \mathrm{V}_{\mathrm{oc}}$ and $\mathrm{FF}$ under illumination, via formation of shunts by promoting the recombination of holes from the HOMO level of P3HT, as discussed in section 2.5. The small decrease of the operational characteristics of the device using the $\mathrm{HZO}$ interlayer could be ascribed to degradation mechanisms common to all devices that equally affect the active layer. Notably, devices using the previously reported by our group 
hydrogen-plasma treated $\mathrm{ZnO}(\mathrm{H}: \mathrm{ZnO})$ electron extraction materials [52], they found to maintain only 40-45 $\%$ of their original PCE values in both type of PSCs when subjected to constant illumination for 40 hours (Fig. S7). This clearly indicates that simple surface modification cannot afford solar cells with prolonged photostabilities since defects present at grain boundaries may be detrimental for the device stability. The simultaneous modification of $\mathrm{ZnO}$ surface and bulk via hydrogen-doping proposed here offers a viable route in achieving PSC devices with superior photostability.

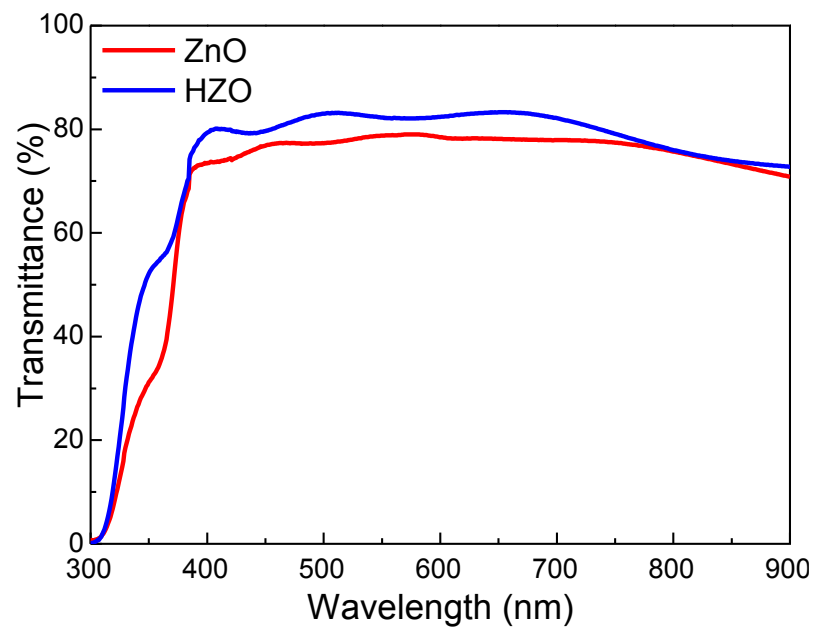

(a)

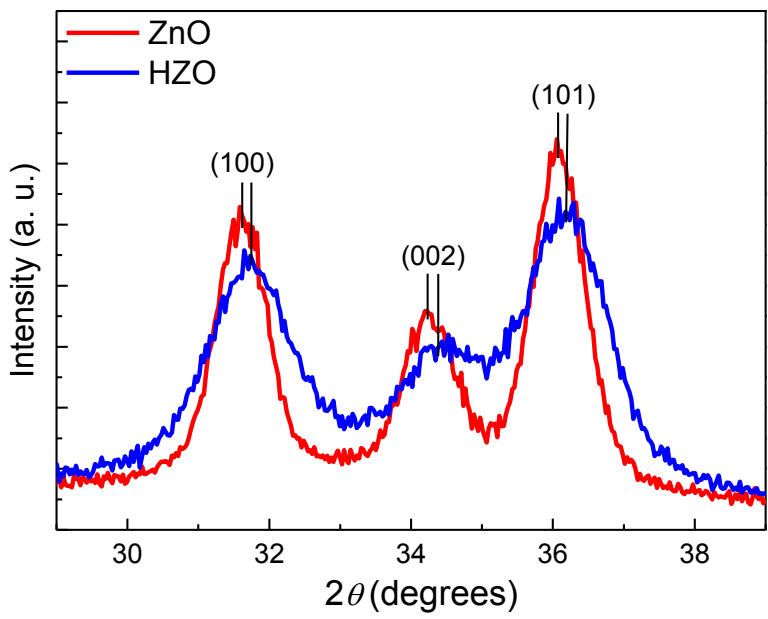

(c)

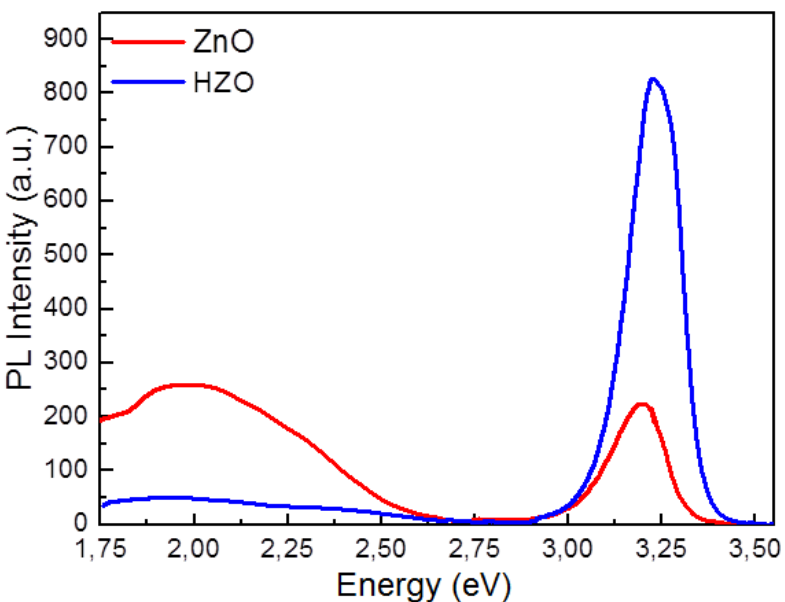

(b)

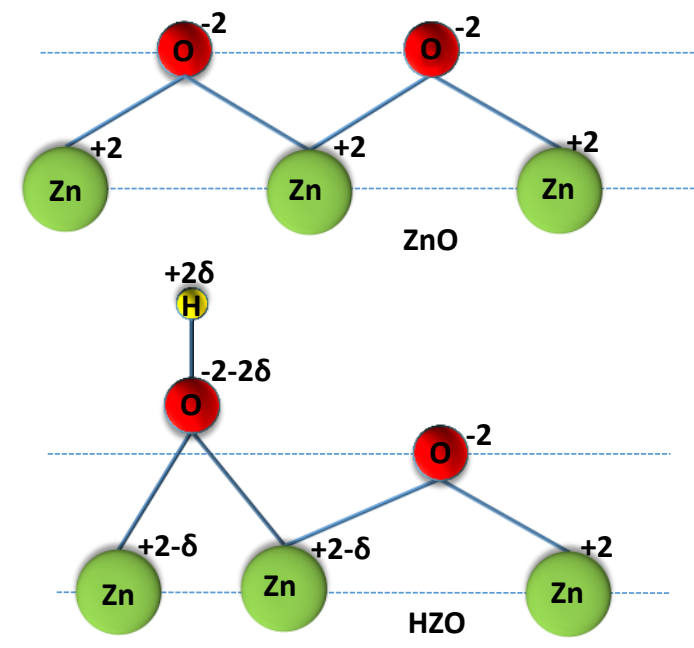

(d)

Figure 6 (a) Transmittance spectra of $\mathrm{ZnO}$ and $\mathrm{HZO}$ films and (b) steady-state PL spectra of the same films. (c) XRD patterns of $\mathrm{ZnO}$ and $\mathrm{HZO}$ films. (d) Schematic illustration of charge redistribution due to hydrogen binding to B-site oxygens. This also results in the weaker $\mathrm{Zn}_{\mathrm{B}} \cdots \mathrm{O}_{\mathrm{B}}$ bonds and consequently, in the $\mathrm{Zn}_{\mathrm{B}} \cdots \mathrm{Zn}_{\mathrm{B}}$ distances being shorter than the $\mathrm{Zn}_{\mathrm{A}} \cdots \mathrm{Zn}_{\mathrm{A}}$ distances.

2.4 Optoelectronic properties and nanoscale structure of $\mathrm{ZnO}$ and $\mathrm{HZO}$ layers. The origin of the improved efficiency and photostability for the devices using the $\mathrm{HZO}$ interlayer as compared to pristine $\mathrm{ZnO}$ may be ascribed to several reasons including a conductivity boost via hydrogen doping [60]. To investigated hydrogen's contribution to the conductivity of $\mathrm{ZnO}$ we performed Hall measurements on samples with a thickness of about $400 \mathrm{~nm}$ (obtained by repeating the spin-coating process ten times while films were dried at $90{ }^{\circ} \mathrm{C}$ between subsequent coating steps). Four-point Van Der Pauw Hall measurements revealed a strong reduction in resistivity of the hydrogen-doped sample (from $91.31 \mathrm{Ohm} \mathrm{cm}$ for air-annealed $\mathrm{ZnO}$ to $0.80 \mathrm{Ohm}$ $\mathrm{cm}$ for the $\mathrm{HZO}$ film) which was caused from a significant increase in electron mobility (from $0.37 \mathrm{~cm}^{2} / \mathrm{Vs}$ for $\mathrm{ZnO}$ to $25.34 \mathrm{~cm}^{2} / \mathrm{V}$ s for $\mathrm{HZO}$ ) and a moderate increase in carrier concentration (from $1.85 \times 10^{17} \mathrm{~cm}^{-3}$ to $3.08 \times 10^{17} \mathrm{~cm}^{-3}$ ). In polycrystalline thin films like $\mathrm{ZnO}$, the electron mobility can be limited mainly by the electron scattering within the grains e.g. the scattering by lattice defects or the electron scattering that occurs at the grain boundaries, due to the potential barrier formed at these locations [61]. In the latter case, the electron mobility should increase if the grain size is increased (because of the decrease of the grain boundary density), as was observed in the case of HZO films (Fig. S4). In addition, when hydrogen is incorporated within the 
film, it passivates lattice defects. The above can explain the significant increase in mobility with consequent decrease in resistivity by almost two orders of magnitude which makes this doped oxide a suitable candidate for use in a broad range of solution based organic and inorganic electronic applications. It is worth noting that, the relatively small increase in carrier concentration of HZO sample implies that this film exhibit no loss of its hole blocking capability which has been previously connected with the increase in carrier concentration [46,59]. In addition, HZO films are highly transparent with the transmittance in the visible region over $84 \%$ while the corresponding value for the $\mathrm{ZnO}$ films is around $78 \%$ (Fig. 6a). Note that the absorption spectra of $\mathrm{ZnO} / \mathrm{HZO}$ films are very similar resulting in the estimation of same energy gap $\left(\mathrm{E}_{\mathrm{g}}=3.3 \mathrm{eV}\right.$, as derived from tauc plot) for both materials (Fig. S8). In the case of $\mathrm{ZnO}$ light absorption at energies below the absorption edge, i.e., within the visible, is induced by transitions between states within the gap and the conduction band. The hydrogenation of the material eliminates these states thus resulting in an increase of transmission [61, 62]. Similar phenomena have been observed in the past in other materials the most striking case being that of amorphous $\mathrm{Si}$, which when un-hydrogenated its band gap is full of states excluding its doping, while when hydrogenated the gap "clears", the material may be doped in $\mathrm{n}$ and p polarities, permitting the formation of electronic devices. This enhancement of transmission is also observed at wavelengths near $900 \mathrm{~nm}$ (see Fig. 6a) also facilitates the formation of interference fringes since the light is permitted to oscillate between the two interfaces of the film (with air and substrate) without to be absorbed. This leads to the formation of an additional maximum observed in Fig. 6a. It must be noted at this point, that if the thickness of the film was different a minimum, instead of a maximum, could equally well have been formed.

Hydrogen-doping-induced passivation of defect states present at surface and grain boundaries of $\mathrm{ZnO}$ is also expected to make our devices very resistive to the degradation processes due to a reduced amount of adsorbed oxygen molecules inside the interlayer. In this context, photoluminescence (PL) spectroscopy is a useful technique to disclose the density of defects on $\mathrm{ZnO}$ and the effect of hydrogen doping on these defects. PL spectra of $\mathrm{ZnO}$ and $\mathrm{HZO}$ samples, obtained at room temperature with excitation at $325 \mathrm{~nm}$, are shown in Fig. 6b. It is apparent that the spectrum of the air-annealed film is dominated by a broad emission in the visible wavelength region which is attributed to native point defects $\left(\mathrm{V}_{\mathrm{Zn}}, \mathrm{V}_{\mathrm{O}}\right)$ of $\mathrm{ZnO}$ showing also a smaller bandto-band sharp near-band emission (NBE) peak at $3.27 \mathrm{eV} \mathrm{[63].} \mathrm{On} \mathrm{the} \mathrm{contrary,} \mathrm{the} \mathrm{spectrum} \mathrm{of} \mathrm{the} \mathrm{HZO} \mathrm{film}$ is only governed by the NBE emission which is significantly enhanced due to the suppression of the defect states that are located within the energy gap of $\mathrm{ZnO}$ and act as recombination centers. Electrons in defects sites are likely to interact with molecular oxygen from the ambient air during film preparation, leading to the formation of chemisorbed $\mathrm{O}_{2}$-species, resulting in severe degradation of $\mathrm{ZnO}$-based devices.

In addition to the above analyses, we performed XRD characterization of the $\mathrm{ZnO}$ and $\mathrm{HZO}$ films prepared on silicon substrates (zoomed-in patterns in Fig. 6c and full-range patterns in Fig. S9). Both films were indexed as wurtzite $\mathrm{ZnO}$ [24]. The diffraction peaks for the hydrogen annealed sample are significantly broader than for the untreated sample, as a result of reduced crystallinity. Moreover, the hexagonal lattice parameters decrease significantly from $\mathrm{ZnO}(a=b=3.241(5) \AA$ and $c=5.192(7) \AA)$ to $\mathrm{HZO}(a=b=$ 3.226(11) $\AA, c=5.160(18) \AA$ ), which indicates shorter inter-planar distances in the hydrogen-annealed sample $[64,65]$. This can be unambiguously attributed to the intercalation of hydrogen within the HZO oxide's lattice, as also indicated by Fourier transform infrared (FTIR) spectra shown in Fig. S10. The peaks observed in the $400-650 \mathrm{~cm}^{-1}$ region are characteristics of the stretching modes of $\mathrm{ZnO}$ [66]. However, in the spectrum of HZO film a significant increase of the broad peak at $3400-3900 \mathrm{~cm}^{-1}$, which consists of absorption lines that are all in the characteristic wavenumber range of the $-\mathrm{OH}$ stretch modes, and the appearance of a band at around $1600 \mathrm{~cm}^{-1}$, which can be assigned to the first overtone of fundamental stretching mode of $-\mathrm{OH}$, indicate the presence $\mathrm{H}$ atoms bonded to $\mathrm{O}$ in the hydrogen annealed sample. The binding of $\mathrm{H}$ to $\mathrm{O}$ shifts the electron density on oxygen away from the $\mathrm{Zn}-\mathrm{O}-\mathrm{Zn}$ bonds, as illustrated schematically in Fig. 6d. Effectively, this is equivalent to the oxygen on site "B" being less electronegative, and as a result, the $\mathrm{Zn}-\mathrm{O}$ bond becoming less ionic, with larger electron density residing on the B-site zinc compared to that in the wurtzite structure (site "A"). The less ionic $\mathrm{Zn}_{\mathrm{B}} \cdots \mathrm{O}_{\mathrm{B}}$ bond results in a longer $\mathrm{Zn}_{\mathrm{B}} \cdots \mathrm{O}_{\mathrm{B}}$ distance, compared to the $\mathrm{Zn}_{\mathrm{A}} \cdots \mathrm{O}_{\mathrm{A}}$ bond away from the hydrogen site. This in turn leads to the $Z_{n} \cdots \mathrm{Zn}_{B}$ distances being shorter than the $Z_{\mathrm{A}} \cdots \mathrm{Zn}_{\mathrm{A}}$ distances, as estimated from the XRD patterns. In addition, the binding of an $\mathrm{H}$ atom to $\mathrm{O}$ results in an increase of electronic occupancy in the bottom of the conduction band with simultaneous passivation of inter-gap defect states (mainly arising from $\mathrm{O}$ dangling bonds) as the $\mathrm{H} 1$ s orbital combines with the $\mathrm{O} 2 \mathrm{p}$ dangling bonds state and results in a fully symmetric bonding state in the valence band, and an antibonding state in the conduction band. The electron that would occupy this antibonding state is then transferred to the conduction-band minimum, making the interstitial hydrogen, $\mathrm{H}_{\mathrm{i}}$, a shallow donor (Fig. S11a). Note that, according to Van der 
Walle, substitutional hydrogen is also a shallow donor in $\mathrm{ZnO}$ since its electron can be transferred to the bottom of the conduction band via bonding with $\mathrm{Zn} 4 \mathrm{~s}$ dangling bonds (Fig. S11b) [49, 50]. Notably, in the XRD pattern of HZO film the intensity of of (002) peak is decreased as compared to those attributed to (100) and (101) planes suggesting that this film has different surface energy (less polar surface) than $\mathrm{ZnO}$, as also indicated by contact angle measurements (Fig. S5). Such a difference in contact angles means that hydrogen treatment results in a less hydrophilic surface that favors the smoother deposition of the organic compounds. In addition, zinc oxide surfaces that contain more polar faces (like air-annealed $\mathrm{ZnO}$ ) might react with the organic semiconductor disrupting the interface [24], which could also be the origin of the faster degradation of the devices based on $\mathrm{ZnO}$.

2.5 Experimental study (XPS/UPS) and theoretical calculations on the electronic structure of $\mathrm{ZnO}$ and HZO layers. Further investigations on constituent elements and the presence of defects at the surface of the samples have been performed using XPS spectroscopy. The representative XPS Zn $2 p$ peaks of air and hydrogen-annealed samples are shown in Fig. S12. Zn $2 p_{3 / 2}$ and Zn $2 p_{1 / 2}$ core level spectral lines appear highly symmetric and their binding energy positions are identical in both films. Both films display a doublet at 1021.6 $\mathrm{eV}$ and $1044.8 \mathrm{eV}$ corresponding to the $\mathrm{Zn} 2 \mathrm{p}_{3 / 2}$ and $2 \mathrm{p}_{1 / 2}$ core levels of stoichiometric $\mathrm{ZnO}$ [67]. Figs $7 \mathrm{a}$ and $7 \mathrm{~b}$ show the XPS O1s peaks of $\mathrm{ZnO}$ and $\mathrm{HZO}$ films. The peaks appear to be asymmetric, indicating the presence of more than one oxygen species in the surface of those films. The deconvoluted O1s peak has two main components at the binding energy positions of 530.4, and $532.0 \mathrm{eV}$. The low binding energy component corresponds to the $\mathrm{O}^{2-}$ state of lattice oxygen $(\mathrm{Zn}-\mathrm{O})$ whereas the high binding energy component is attributed to adsorbed $\mathrm{OH} / \mathrm{H}_{2} \mathrm{O}$ or other surface oxygen species at the films surface as well as to oxygen vacancies $\left(\mathrm{V}_{\mathrm{O}}\right)$ $[68,69]$. The contribution of the high binding energy component is smaller in the HZO film which may indicates that hydrogen annealing reduces oxygen vacancies since FTIR study clearly evidenced that $-\mathrm{OH}$ species are increased in the HZO film. Reduced density of oxygen vacancies results in removal of chemisorbed oxygen promoting the improvement of device performance and overall stability.

In addition, UPS spectroscopy was used to experimentally probe the electronic structure of the valence band of $\mathrm{ZnO}$ and HZO layers on FTO substrates. Since these samples were prepared ex-situ in order to eliminate the surface contamination before introducing to ultra-high vacuum they were transferred into argon filled vials. The UPS spectrum of $\mathrm{ZnO}$ film (Fig. 7c) shows two distinct peaks at $\sim 5.0 \mathrm{eV}$ and $\sim 11.0 \mathrm{eV}$ binding energies which arise from the $\mathrm{O} 2 \mathrm{p}$ and $\mathrm{Zn} 3 \mathrm{~d}$ bands, respectively. For the $\mathrm{ZnO}$ film a work function $\left(\mathrm{W}_{\mathrm{F}}\right)$ of $4.1 \mathrm{eV}$ is determined, while $\mathrm{HZO}$ shows a reduced $\mathrm{W}_{\mathrm{F}}$ of $3.9 \mathrm{eV}$. The $\mathrm{W}_{\mathrm{F}}$ shift towards lower values of the $\mathrm{HZO}$ sample can be explained as follows: During hydrogen annealing of $\mathrm{ZnO}-\mathrm{OH}$ groups are formed on its surface (as well as its bulk) as discussed above. Hydroxyl is however electrically polar, with a dipole moment of 1.67 Debye $\left(5.57 \times 10^{-30} \mathrm{Cm}\right)$ [70]. It is thus reasonable to assume that the formation of hydroxyl groups on the surface of HZO sample would readily lead to the formation of an electrical dipole which consequently reduces about $0.2 \mathrm{eV}$ the surface work function of the sample. The reduction in work function between $\mathrm{ZnO}$ and HZO is expected to increase the built-in voltage across the organic bulk in the photodiode, improving the electron extraction properties of the cathode, and thus increasing the $\mathrm{V}_{\text {oc }}$ of the device as observed above. The energy level alignment of various layers used in our devices considering vacuum level alignment (before contact) is illustrated in Fig. 7d demonstrating that the $\mathrm{W}_{\mathrm{F}}$ of HZO nearly aligns with the LUMO level of $\mathrm{PC}_{70} \mathrm{BM}$ while also locates closer to the $\mathrm{LUMO}$ of $\mathrm{IC}_{60} \mathrm{BA}$ as compared to $\mathrm{ZnO}$ thus facilitating electron extraction (the energy levels of organic materials were taken from the literature [71], while the $\mathrm{W}_{\mathrm{F}}$ of $\mathrm{MoO}_{\mathrm{x}}$ was previously measured by our group [72]). Since the reported $\mathrm{W}_{\mathrm{F}}$ values and the associated negative integer charge transfer states of e.g. $\mathrm{PC}_{70} \mathrm{BM}$ are within the range of 4.3-4.6 eV [73], a negative interfacial dipole (with its negative pole towards $\mathrm{PC}_{70} \mathrm{BM}$ ) is also expected to be formed at the zinc oxide/ $\mathrm{PC}_{70} \mathrm{BM}$ interface as both substrates' work function is smaller than that of the organic. Such negative dipole, which is larger in the case of HZO material, is beneficial for the device performance as the associated built-in dipole field may further assist electron transfer. Overall, the application of hydrogen-doping greatly enhances the electron selectivity of zinc oxide material. Note that, when both types of electron transport layers have been placed under 1 hour of $100 \mathrm{~mW} / \mathrm{cm}^{2}$ full $1.5 \mathrm{AM}$ illumination in air, we found that their $\mathrm{W}_{\mathrm{F}}$ increased to $4.3 \mathrm{eV}$ (Fig. $\mathrm{S} 13)$. This is in agreement with previous studies demonstrating that for UV-light soaking of $\mathrm{ZnO}$ in the presence of oxygen, the work function increases which was attributed to a decrease of the oxygen-defect component of the $\mathrm{ZnO}$ caused by oxygen atom vacancy filling occurring mainly at the surface of the $\mathrm{ZnO}$ films as a result of oxygen readsoprtion [74]. On the contrary, hydrogen-doping studied here induces a 
decrease in work function and surface-desorption of chemisorbed oxygen resulting in effective passivation of defect states via the formation of hydroxyl group.

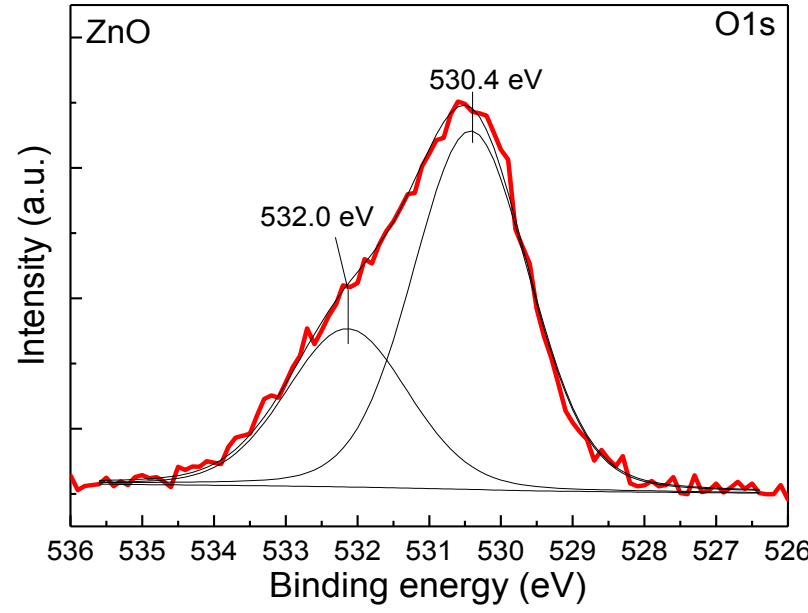

(a)

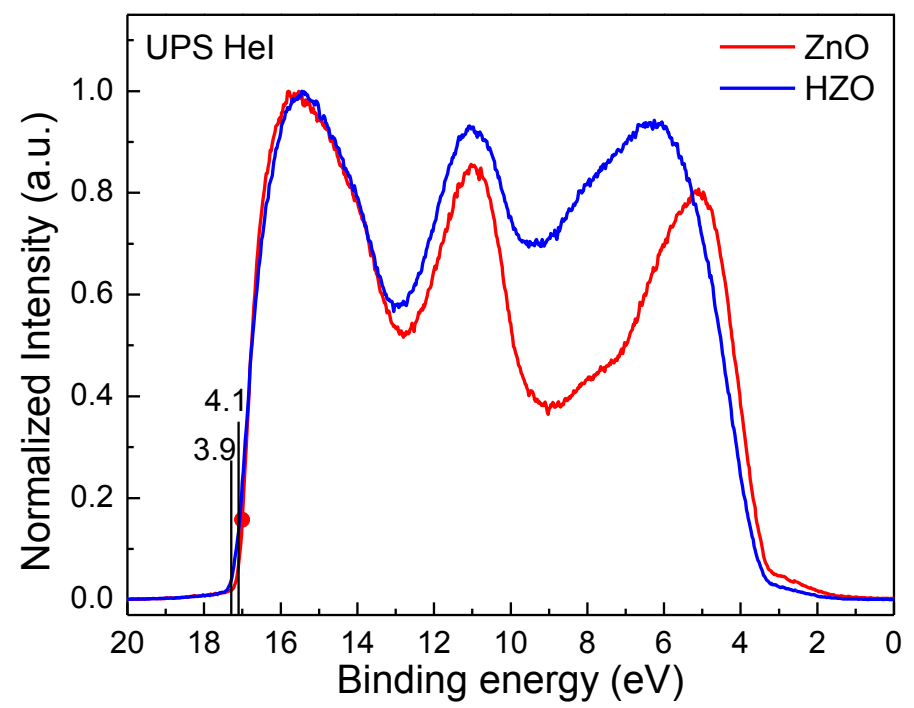

(c)

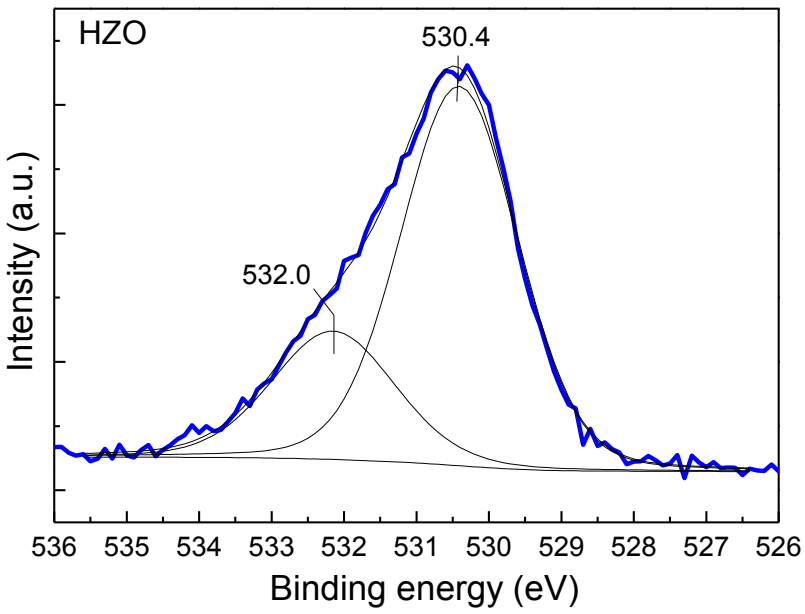

(b)

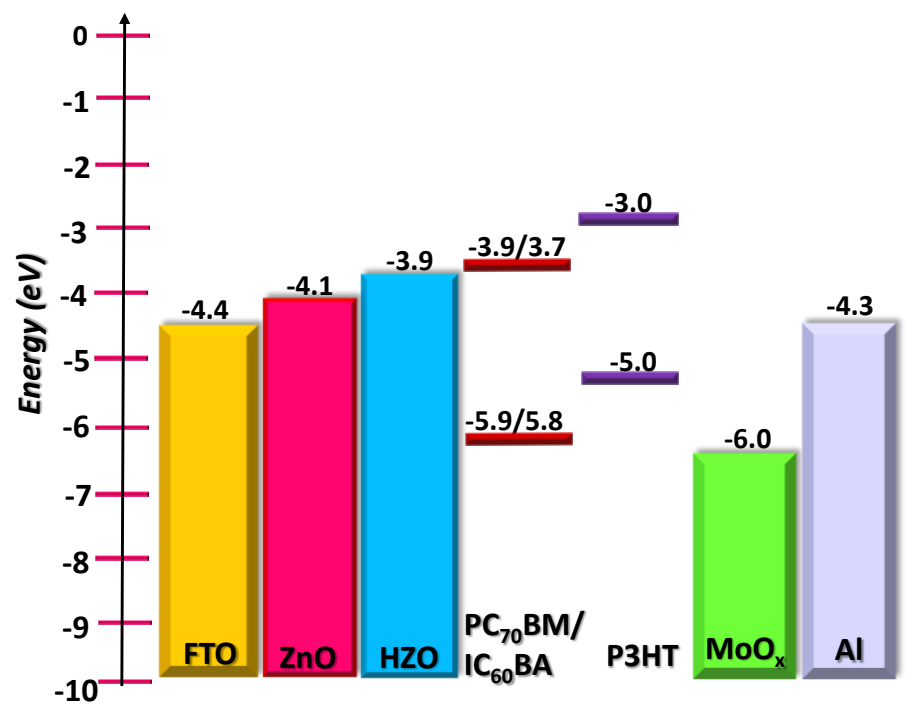

(d)

Figure 7 XPS O 1s peaks of (a) ZnO and (b) HZO samples. (c) UPS spectra taken on the ZnO and HZO films deposited on an FTO substrate. (d) Schematic energy level diagram of various layers used in the device structure considering energy level alignment (before contact).

To further support our argument that passivation of oxygen vacancies might be the main reason for enhanced performance and stability of PSCs we also carried out Density Functional Theory (DFT) calculations. We focus at the O-terminated $\mathrm{ZnO}(0002)$ surface (Fig. S14a), hereafter mentioned simply as the $\mathrm{ZnO}$ surface, which has the lowest surface energy in the O- and H-rich limits [75]. The density of states (DOS) of the $\mathrm{ZnO}$ surface is plotted in Fig. 8a. We observe that states located $0.1 \mathrm{eV}$ below the valence band maximum mainly consist of $\mathrm{O} 2 p$ levels with nearly no contribution from $\mathrm{Zn}$ states. We also observe the appearance of sharp states located at $-1.4,-1.1,-0.7$ and $0.2 \mathrm{eV}$ (Fig. 8a and S14c), which are related mostly to surface oxygen $p$ and hybridized $d$ orbitals. This provides proof of our hypothesis that surface oxygen unsaturated bonds are mainly responsible for trap states appearing at the bottom of the $\mathrm{ZnO}$ conduction band. Next, the $\mathrm{ZnO}(0002)$ slab was optimized after all surface oxygen orbitals were saturated via bonding with hydrogen atoms to form hydroxyl groups (Fig. S14b). The coverage density of hydrogen was calculated to be $\rho=10.93 \cdot 10^{14} \mathrm{~cm}^{-2}$ and the energy released during the formation of each hydroxyl group was found to be $3.72 \mathrm{eV}$, showing that this process is energetically favorable. In order to examine the effect of hydrogen doping on the surface electronic structure, we plot the density of states after having introduced (i) interstitial hydrogen atoms bonded to surface oxygen forming hydroxyl groups, and (ii) a hydrogen substitutional defect, replacing an oxygen vacancy, following previous work by Janotti et al. [51]. (Fig. 8b). We observe that when hydrogen doping occurs, there is a considerable suppression of the unsaturated surface oxygen states. Surface hydrogen 
doping provides for electron transfer from hydrogen to oxygen atoms, reducing the electronegativity of the latter. This is confirmed via Bader charge analysis performed on the $\mathrm{ZnO}$ slab before and after hydrogen doping, which shows that the formation of surface hydroxyl groups results in charge transfer of $1.08 \pm 0.08$ electrons, on average, to surface oxygen atoms. At the same time the $\mathrm{Zn}-\mathrm{O}$ bond becomes less ionic, which in turn results in higher Zn $3 d$ and $4 s$-orbital occupancies, and consequently more metallic behavior. Similar results were obtained when hydrogen doping of bulk $\mathrm{ZnO}$ occurs (Fig. S15). Taking into account all the above results, we conclude that hydrogen doping occurring during hydrogen annealing of $\mathrm{ZnO}$ is responsible for the enhanced performance and exceptional stability of our devices which is in agreement with our hypothesis.

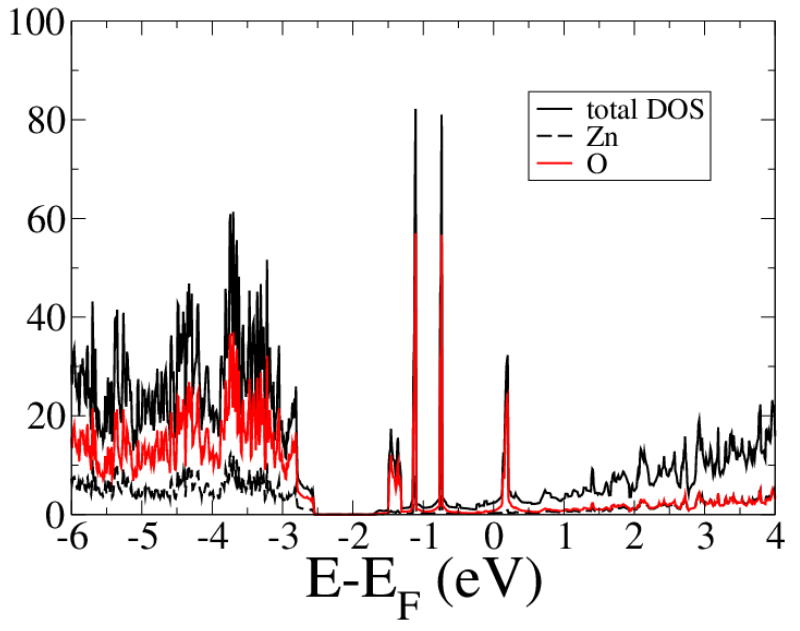

(a)

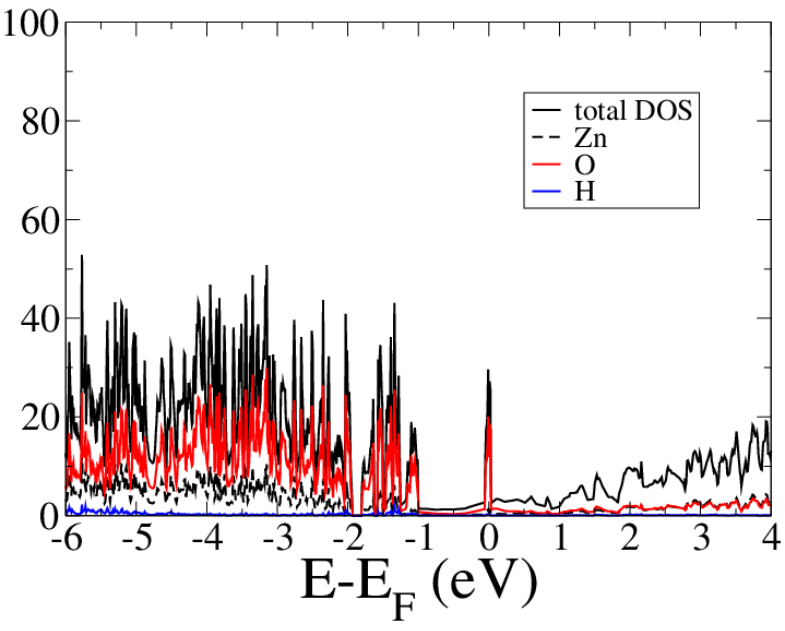

(b)

Figure 8 (a) The density of states of the $\mathrm{ZnO}(0002)$ surface; (b) The density of states of the $\mathrm{ZnO}(0002)$ surface after interstitial hydrogen atoms bonded to surface unsaturated oxygen atoms, with the coverage density of hydrogen calculated to be $\rho=13.66 \cdot 10^{14} \mathrm{~cm}^{-2}$ including a substitutional hydrogen defect (Fig. 14b). The total DOS is plotted in solid black line, along with the partial DOS for zinc atoms (black dashed line), oxygen atoms (red solid line), and hydrogen atoms (blue solid line). The Fermi level is set to $0 \mathrm{eV}$.

\section{Conclusions}

To summarize, the effectiveness of hydrogen-doping of $\mathrm{ZnO}$ on the performance and stability of polymer solar cells has been investigated. It was revealed that simple hydrogen-annealing of $\mathrm{ZnO}$ (instead of airannealing) significantly boosts the efficiency while simultaneously strengthens the stability of the cell. Stemming from synergistic effects, the hydrogen-annealed sample offers several advantages over its airannealed counterpart including less density of surface traps and defects at grain boundaries followed by removal of chemisorbed oxygen species, more efficient charge separation, reduced electron extraction barrier and better transport capability due to improved conductivity. The combined effects resulted in a remarkable enhancement of $\mathrm{V}_{\mathrm{oc}}, \mathrm{J}_{\mathrm{sc}}$ and FF in HZO based PSCs, irrespective of the acceptor used in combination with P3HT as polymer donor in the photoactive blend. Preliminary results taken on PTB7:PC 70 BM-based devices indicated the universality of our approach. In addition, removal of chemisorbed oxygen following the passivation of defect states is suggested to explain the substantial improvement of the stability of the resulting devices when exposed to ambient or are under prolonged illumination. Based on our results, we believe that our prescription of gaining control on the properties of $\mathrm{ZnO}$ interlayers based on the interplay of electron donor capability of intercalated hydrogen and induced surface defect passivation constitutes a step forward towards not only efficient PSCs, but also any type of ZnO-based applications.

\section{Experimental section}

Preparation of $\mathrm{ZnO}$ and $\mathrm{HZO}$ layers. Solution-processed $\mathrm{ZnO}$ films were prepared following a sol-gel method using zinc acetate in 2-methoxyethanol:2-amino-ethanol as a precursor solution [76]. The solution with a concentration of $0.50 \mathrm{M}$ was filtered by a $0.45 \mu \mathrm{m}$ pore size nylon membrane and then spin-coated at $3000 \mathrm{rpm}$. Zinc acetate was purchased from Sigma-Aldrich and used without further purification. The $\mathrm{ZnO}$ films were then annealed either in air or in pure hydrogen environment for $20 \mathrm{~min}$. Hydrogen annealing was made in a furnace equipped with a quartz chamber, a temperature control system, a vacuum and a gas line. Samples were positioned in the chamber on a graphite susceptor, which heated with the aid of three tungsten 
lamps of $1000 \mathrm{~W}$ each. The temperature of the susceptor (and of the samples on it) was controlled with an automatic temperature control system, which was receiving feedback from a thermocouple positioned in a hole on the graphite and was controlling the power of the lamps. After loading the samples, the chamber was evacuated down to $210^{-2}$ Torr. Then a nitrogen stream was allowed to flow throw it to maintain a pressure of 0.1 Torr and the temperature was raised to the desired point $\left(100-350{ }^{\circ} \mathrm{C}\right)$. After the pre-set temperature was reached, the chamber was evacuated again down to $210^{-2}$ Torr and the hydrogen was introduced in it at a pressure of 1 Torr. At the end of the annealing the chamber was evacuated from hydrogen, nitrogen was introduced, the heating lamps were turn off and the samples were left to cool down to $70{ }^{\circ} \mathrm{C}$ under 0.1 Torr of nitrogen.

Device Fabrication. Inverted polymer solar cells were fabricated on fluorinated tin oxide (FTO) coated glass which were purchased from Sigma-Aldrich and served as the cathode electrode. Substrates were ultrasonically cleaned with a standard solvent regiment $(15 \mathrm{~min}$ each in detergent, acetone, isopropanol and de-ionized water). The $\mathrm{ZnO}$ layer (with a thickness of $40 \mathrm{~nm}$ ) was then deposited followed by appropriate annealing and deposition of the photoactive layer. The active layer consisted of P3HT:PC $70 \mathrm{BM}$ blend $\left(10 \mathrm{mg} \mathrm{ml}^{-1}\right.$ for P3HT, $8 \mathrm{mg} \mathrm{ml}^{-1}$ for $\mathrm{PC}_{70} \mathrm{BM}$ in 1,2 dichlorobenzene) with a thickness of $150 \mathrm{~nm}$ or P3HT:IC $60 \mathrm{BA}\left(17 \mathrm{mg} \mathrm{ml}^{-1}\right.$ for $\mathrm{P} 3 \mathrm{HT}, 17 \mathrm{mg} \mathrm{ml}^{-1}$ for $\mathrm{IC}_{60} \mathrm{BA}$ in 1,2-dichlorobenzene) with a thickness of $200 \mathrm{~nm}$. After spin coating (at 600 $\mathrm{rpm}$ for $40 \mathrm{~s}$ for P3HT:PC $70 \mathrm{BM}$ and at $800 \mathrm{rpm}$ for $30 \mathrm{~s}$ for P3HT:IC $60 \mathrm{BA}$ ) the photoactive layers were left to dry for about $30 \mathrm{~min}$ and then annealed at $150{ }^{\circ} \mathrm{C}$ for $10 \mathrm{~min}$. PTB7:PC $70 \mathrm{BM}$ was deposited via spin coating at $1000 \mathrm{rpm}$ for $90 \mathrm{~s}$ from solutions with concentration $10 \mathrm{mg} \mathrm{ml}^{-1}$ for PTB7, $15 \mathrm{mg} \mathrm{ml}^{-1}$ for PC70BM in 1,2 dichlorobenzene where $3 \%$ per volume of DIO was added to deliver a thickness of $85 \mathrm{~nm}$ and then was left to dry without being subjected to any post-deposition annealing. Note that all depositions and thermal annealing treatments of P3HT:IC ${ }_{60} \mathrm{BA}$ and $\mathrm{PTB} 7: \mathrm{PC}_{70} \mathrm{BM}$ films were carried out in the inert environment of an argon filled glove-box with oxygen and humidity levels below $1.0 \mathrm{ppm}$. Then, an approximately $30 \mathrm{~nm}$ thick understoichiometric molybdenum oxide $\left(\mathrm{MoO}_{\mathrm{x}}\right)$ layer was deposited on top of the photoactive layer to serve as the hole extraction layer [77]. The devices were completed with a $150 \mathrm{~nm}$ thick aluminium anode, deposited in a dedicated thermal evaporator at a pressure of $10^{-6}$ Torr through a shadow-mask, which defined the device active area to be equal to $12.56 \mathrm{~mm}^{2}$. The devices were then measured in air at room temperature without additional encapsulation. All chemicals were purchased from Sigma-Aldrich and used with no further purification.

Measurements and Instrumentation. X-ray photoelectron spectra (XPS) and Ultraviolet Photoelectron Spectra (UPS) were recorded by Leybold EA-11 electron analyzer operating in constant energy mode at pass energy of $100 \mathrm{eV}$ and at a constant retard ratio of $4 \mathrm{eV}$ for XPS and UPS respectively. All binding energies were referred to the $\mathrm{C} 1 \mathrm{~s}$ peak at $284.8 \mathrm{eV}$ of surface adventitious carbon, respectively. The $\mathrm{X}$-ray source for all measurements was a nonmonochromatized $\mathrm{Al} \mathrm{Ka}$ line at $1486.6 \mathrm{eV}(12 \mathrm{keV}$ with $20 \mathrm{~mA}$ anode current). The valence band spectra of $\mathrm{Zn}$ oxides were evaluated after recording the UPS spectra of about $400 \mathrm{~nm}$ thick films deposited on an FTO substrate. For the UPS measurements, the He I (21.22 eV) excitation line was used. A negative bias of $12.22 \mathrm{~V}$ was applied to the samples during UPS measurements in order to separate secondary electrons originating from sample and spectrometer and to estimate the absolute work function value from the high BE cut-off region of the UPS spectra. The analyzer resolution is determined from the width of the $\mathrm{Au}$ Fermi edge to be $0.16 \mathrm{eV}$. The electrical resistivity, Hall mobility and free carrier concentration were determined by Hall-effect measurements at room temperatures in Van der Pauw geometry using a constant magnetic field of $0.5 \mathrm{~T}$. The steady state photoluminescence spectra of $\mathrm{P} 3 \mathrm{HT}$ on various substrates were taken by means of a Fluoromax spectrometer (Horiba) upon excitation at $550 \mathrm{~nm}$. The films were placed on a specific holder for solid samples and the spectra were corrected for the sensitivity of the detector. The PL dynamics of the samples were studied under magic angle conditions, by using a femtosecond upconversion technique. The excitation of the samples was realized by means of the second harmonic of a Ti:Sapphire laser at $400 \mathrm{~nm}$. The average power was less than $3 \mathrm{~mW}$ while the repetition frequency was 80 MHz. The PL of the samples was collected and focused together with the remaining fundamental fs laser beam on a $0.5 \mathrm{~mm}$ BBO crystal to produce frequency mixing. The upconverted beam passed through an iris, filters and a monochromator and was detected by a photomultiplier. The Instrument's Response Function (IRF) was approximately $150 \mathrm{fs}$. A three-exponential function convoluted with the IRF was used for fitting the dynamics. EQE measurements were carried out using an Autolab PGSTAT-30 potentiostat, with a $300 \mathrm{~W}$ Xe lamp in combination with an Oriel 1/8 monochromator for dispersing the light in an area of $0.5 \mathrm{~cm}^{2}$. A Thorlabs silicon 
photodiode was used for the calibration of the spectra. All measurements were performed in air. X-ray diffraction (XRD) structural analysis was performed using a Siemens D500 diffractometer with $\mathrm{Cu}-\mathrm{Ka}$ radiation. Absorption measurements were taken using a Perkin Elmer Lamda $40 \mathrm{UV} / \mathrm{V}$ is spectrophotometer. FTIR transmission spectra of ZnO films were obtained on a Bruker Tensor 27 spectrometer (at $4 \mathrm{~cm}^{-1}$ resolution, 64 scans) with a DTGS detector. The thicknesses of films were measured with an Ambios XP-2 profilometer and a M2000 Woolam ellipsometer. Current density-voltage characteristics of the fabricated solar cells were measured with a Keithley 2400 source-measure unit. Cells were illuminated with a Xe lamp and an AM 1.5G filter to simulate solar light illumination conditions with an intensity of $100 \mathrm{~mW} / \mathrm{cm}^{2}$ (1 sun), as was recorded with a calibrated silicon photodiode. To accurately define the active area of all devices we used aperture masks during the measurements with their area equal to those of the Al contacts $\left(12.56 \mathrm{~mm}^{2}\right)$.

Computational part. All theoretical calculations were carried out using the Vienna Ab Initio Simulation Package (VASP). Plane-wave basis sets and the Perdew-Burke-Ernzerhof (PBE) gradient-corrected exchangecorrelation functional was used throughout the computational part. We incorporated an effective Hubbard U parameter equal to $8.5 \mathrm{eV}$ as implemented and tested by Li et al [78]. All calculations were performed via the projector augmented wave (PAW) method with a plane-wave cut-off energy of $400 \mathrm{eV}$ and a $\Gamma$ centered kpoint grid of $4 \times 4 \times 4$ for the bulk and $8 \times 8 \times 1$ for the surface calculations. The tetrahedron method with Blöchl corrections of a width of $0.2 \mathrm{eV}$ was used to determine how partial occupancies are set for each wave function. The $\mathrm{ZnO}$ surface slab was constructed after $\mathrm{PBE}+\mathrm{U}$ ion optimization, excluding volume, was performed on bulk $\mathrm{ZnO}$ at its crystallographic coordinates; these were taken from work done by Kisi et al [79]. An orthorhombic unit cell was used of dimensions $a=6.50 \AA, b=5.63 \AA$ and $c=5.21 \AA$, including $8 \mathrm{Zn}$ and 8 $\mathrm{O}$ atoms. The $\mathrm{ZnO}$ (0002) surface, which is the most stable and exposed crystal surface of $\mathrm{ZnO}$ [75], was modeled using $20 \mathrm{Zn}$ and $24 \mathrm{O}$ atoms within an orthorhombic cell of dimensions $\mathrm{a}=6.50 \AA, \mathrm{b}=5.63 \AA$ and $\mathrm{c}=40 \AA$. All surface cells were separated by a vacuum space of $\sim 30 \AA$ along z-axis. Geometry optimization,

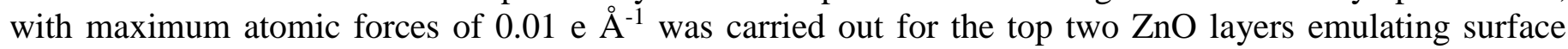
relaxation, while the bottom three layers were kept fixed at their crystallographic coordinates representing "bulk" ZnO.

\section{Acknowledgements}

This work was performed in the framework of "YDISE" project within GSRT's KRIPIS action, funded by Greece and the European Regional Development Fund of the European Union under NSRF 2007-2013 and the Regional Operational Program of Attica. TP acknowledges use of Hartree Centre computational resources via the $3^{\text {rd }}$ BlueJoule Access Programme, under project No. HCBG125, funded by the U.K. Science and Technology Facility Council (STFC).

\section{Supporting Information}

Additional Figures are included in the Supporting Information: J-V characteristics of polymer solar cells based on $\mathrm{ZnO}$ electron transport layers processed under different annealing conditions, J-V characteristics and plots of $\mathrm{V}_{\mathrm{oc}}$ versus light intensity of PTB7:PC $70 \mathrm{BM}$, AFM topographies and contact angle measurements of $\mathrm{ZnO}$ and $\mathrm{HZO}$ layers, thin and thick photoactive films nanomorphology, UV-vis absorption spectra of different $\mathrm{ZnO}$ layers, XRD patterns and FTIR measurements of $\mathrm{ZnO}$ and $\mathrm{HZO}$ layers, energy band diagrams, $\mathrm{Zn} 2 \mathrm{p}$ XPS peaks of $\mathrm{ZnO}$ and $\mathrm{HZO}$ layers, UPS spectra of $\mathrm{ZnO} / \mathrm{HZO}$ layers before and after light exposure, DFT calculated density of states.

\section{References}

[1] G. Gao, J. C. Hummelen, F. Wudl, A. J. Heeger, Science 270 (1995) 1789-1791.

[2] M. A Green, K. Emery, Y. Hishikawa, W. Warta, E. D. Dunlop, Prog. Phot. Res. Appl. 20 (2013) 12-20.

[3] S. Mathew, A. Yella, P. Gao, R. Humphry-Baker, B. F. E. Curchod, N. Ashari-Astani, I. Tavernelli, U. Rothlisberger, Md. Khaja Nazeeruddin, M. Grätzel, Nat. Chem. 6 (2014) 242-247.

[4] N. K. Noel, S. D. Stranks, A. Abate, C. Wehrenfennig, S. Guarnera, A. Haghighirad, A. Sadhanala, G. E Eperon, S. K. Pathak, M. B Johnston, L. Herz, H. Snaith, Energy Environ. Sci. 7 (2014) 3061-3068.

[5] Z. He, B. Xiao, F. Liu, H. Wu, Y. Yang, S. Xiao, C. Wang, T. P. Russell, Y. Cao., Nature Photon. 9 (2015) 174-17.

[6] Z. Yin, J. Wei, Q. Zheng, Adv. Sci. (2016) 1500362.

[7] Y. Li, Acc. Chem. Res. 45 (2012) 723-733. 
[8] H.-L. Yipa, A. K.-Y. Jen, Energy Environ. Sci. 5 (2012) 5994-6011.

[9] C. K. Song, A. C. White, L. Zeng, B. J. Leever, M. D. Clark, J. D. Emery, S. J. Lou, A. Timalsina, L. X. Chen, M. J. Bedzyk, T. J. Marks, ACS Appl. Mater. Interfaces 5 (2013) 9224-9240.

[10] S. Chen, J. R. Manders, S.-W. Tsang, F. So, J. Mater. Chem. 22 (2012) 24202-24212.

[11] J. You, C.-C. Chen, L. Dou, S. Murase, H.-S. Duan, S. Hawks, T. Xu, H. J. Son, L. Yu, G. Li, Y. Yang, Adv. Mater. 24 (2012) 5267-5272.

[12] R. M. Hewlett, M. A. McLachlan, Adv. Mater. 28 (2016) 3893-3921.

[13] S. Trost, T. Becker, K. Zilberberg, A. Behrendt, A. Polywka, R. Heiderhoff, P. Görrn, T. Riedl, Sci. Rep. 5 (2014) 7765.

[14] J. Gilot, M. M. Wienk, R. A. J. Janssen, Appl. Phys. Lett. 90 (2007) 143512.

[15] H. Zhang, T. Stubhan, N. Li, M. Turbiez, G. J. Matt, T. Ameri, C. J. Brabec, J. Mater. Chem. A (2014) 18917-18923.

[16] A. Kohan, G. Ceder, D. Morgan, C. Van de Walle, Phys. Rev. B 61 (2000) 15019.

[17] A. Janotti, C. G. Van de Walle, Phys. Rev. B 76 (2007) 5202.

[18] A. Janotti, C. G. Van de Walle, Appl. Phys. Lett. 87 (2005) 122102-3.

[19] K. H. Tam, C. K. Cheung, Y. H. Leung, A. B. Djurišić, C. C. Ling, C. D. Beling, S. Fung, W. M. Kwok, W. K. Chan, D. L. Phillips, L. Ding, W. K. Ge, J. Phys. Chem. B 110 (2006) 18917-18923.

[20] M. Hartel, S. Chen, B. Swerdlow, H.-Y. Hsu, J. Manders, K. Schanze, F. So, ACS Appl. Mater. Interfaces 5 (2013) 7215-7218.

[21] A. Gadisa, Y. Liu, E. T. Samulski, R. Lopez, Appl. Phys. Lett. 100 (2012) 253903

[22] Y. Jin, J. Wang, B. Sun, J. C. Blakesley, N. C. Greenham, Nano Lett. 8 (2008) 1649-1653.

[23] B. A. MacLeod, B. J. T. de Villers, P. Schulz, P. F. Ndione, H. Kim, A. J. Giordano, K. Zhu, S. R. Marder, S. Graham, J. J. Berry, A. Kahn, D. C. Olson, Energy Environ. Sci. 8 (2015) 592-601.

[24] V. Gavryushin, G. Raciukaitis, D. Juodzbalis, A. Kazlauskas, V. Kubertavicius, J. Cryst. Growth 138 (1994) 924-933.

[25] S. Trost, K. Zilberberg, A. Behrendt, A. Polywka, P. Görrn, P. Reckers, J. Maibach, T. Mayer, T. Riedl, Adv. Energy Mater. 3 (2013) 1437-1444.

[26] M. Prosa, M. Tessarolo, M. Bolognesi, O. Margeat, D. Gedefaw, M. Gaceur, C. Videlot Ackermann, M. R. Andersson, M. Muccini, M. Seri, J. Ackermann, ACS Appl. Mater. Interfaces 2016, 8, 1635-1643.

[27] S. Wilken, J. Parisi, H. Borchert, J. Phys. Chem. C 118 (2014) 19672-19682.

[28] M. R. Lilliedal, A. J. Medford, M. V. Madsen, K. Norrman, F. C. Krebs, Sol. Energy Mater. Sol. Cells 94 (2010) 2018-2031.

[29] A. J. Morfa, B. I. MacDonald, J. Subbiah, J. J. Jasieniak, Sol. Ener. Mater. Sol. Cells 124 (2014) 211216.

[30] S. Wilken, J. Parisi, H. Borchert, J. Phys. Chem. C 118 (2014) 19672-19682.

[31] Q. Bao, X. Liu, Y. Xia, F. Gao, L.-D. Kauffmann, O. Margeat, J. Ackermann, M. Fahlman, J. Mater. Chem. A 2 (2014) 17676-17682.

[32] H.-L. Yip, S. K. Hau, N. S. Baek, H. Ma, A. K.-Y. Jen, Adv. Mater. 20 (2008) 2376-2382.

[33] Y. E. Ha, M. Y. Jo, J. Park, Y.-C. Kang, S. I. Yoo, J. H. Kim, J. Phys. Chem. C 11(2013) 2646-2652.

[34] Y.-S. Cheng, S.-H. Liao, Y.-L. Li, S.-A. Chen, ACS Appl. Mater. Interfaces 5 (2013) 6665-6671.

[35] J. J. Intemann, K. Yao, Y.-X. Li, H.-L. Yip, Y. X. Xu, P.-W. Liang, C.-C. Chueh, F.-Z. Ding, X. Yang, X. Li, Y. Chen, A. K.-Y. Jen, Adv. Funct. Mater. 24 (2013) 1465-1473.

[36] I. Lange, S. Reiter, M. Pätzel, A. Zykov, A. Nefedov, J. Hildebrandt, S. Hecht, S. Kowarik, C. Wöll, G. Heimel, D. Neher, Adv. Funct. Mater. 24 (2014) 7014-7024.

[37] S. Bai, Y. Jin, X. Liang, Z. Ye, Z. Wu, B. Sun, Z. Ma, Z. Tang, J. Wang, U. Würfel, F. Gao, F. Zhang, Adv. Energy Mater. 5 (2015) 1401606.

[38] S. Shao, K. Zheng, T. Pullerits, F. Zhang, ACS Appl. Mater. Interfaces 5 (2013) 380-385.

[39] S. B. Jo, J. H. Lee, M. Sim, M. Kim, J. H. Park, Y. S. Choi, Y. Kim, S.-G. Ihn, K. Cho, Adv. Energy Mater. 1 (2011) 690-698.

[40] T. Hu, F. Li, K. Yuan, Y. Chen, ACS Appl. Mater. Interfaces 5 (2013) 5763-5770.

[41] X. Liu,X. Li, Y. Li,C. Song,L. Zhu,W.Zhang, H.-Q.Wang, J. Fang,Adv. Mater. 28(2016) 7405-7412.

[42] T. Stubhan, I. Litzov, N. Li, M. Salinas, M. Steidl, G. Sauer, K. Forberich, G. J. Matt, M. Halik, C. J. Brabec, J. Mater. Chem. A 1 (2013) 6004-6009.

[43] A. Puetz, T. Stubhan, M. Reinhard, O. Loesch, E. Hammarberg, S. Wolf, C. Feldmann, H. Kalt, A. Colsmann, U. Lemmer, Sol. Energy Mater. Sol. Cells 95 (2011) 579-585. 
[44] A. Savva, S. A. Choulis, Appl. Phys. Lett. 102 (2013) 233301.

[45] H. Woo Choi, K.-S. Lee, N. David Theodore, T. L. Alford, Sol. Energy Mater. Sol. Cells 117 (2013) 273-278.

[46] K. P. Musselman, S. Albert-Seifried, R. L. Z. Hoye, A. Sadhanala, D. Muñoz-Rojas, J. L. MacManusDriscoll, R. H. Friend, Adv. Funct. Mater. 24 (2014) 3562-3570.

[47] J. Adams, G. D. Spyropoulos, M. Salvador, N. Li, S. Strohm, L. Lucera, S. Langner, F. Machui, H. Zhang, T. Ameri, M. M. Voigt, F. C. Krebs, C. J. Brabec, Energy Environ. Sci. 8, (2015) 169-176.

[48] N. K Elumalai, C. Vijila, R. Jose, A. Uddin, S. Ramakrishna, Mater. Renew. Sustain. Energy 4:11 (2015) 1-25.

[49] C. G. Van de Walle, Phys. Rev. Lett. 85 (2000) 1012-1015.

[50] C. G. Van de Walle, J. Neugebauer, Nature 423 (2003) 626-628.

[51] A. Janotti, C. G. Van de Walle, Nat. Mater. 6 (2007) 44-47.

[52] V. Papamakarios, E. Polydorou, A. Soultati, N. Droseros, D. Tsikritzis, A. M. Douvas, L. Palilis, M. Fakis, S. Kennou, P. Argitis, M. Vasilopoulou, ACS Appl. Mater. Interfaces 8 (2016) 1194-1205.

[53] H. L. Gao, X. W. Zhang, J. H. Meng, Z. G. Yin, L. Q. Zhang, J. L. Wu, X. Liu, J. Mater. Chem. 3 (2015) 3719-3725.

[54] B.-Y. Oh, M.-C. Jeong, D.-S. Kim, W. Lee, J.-M. Myoung, J. Cryst. Growth 281 (2005) 475-480.

[55] Z. Kam, X. Wang, J. Zhang, J. Wu, ACS Appl. Mater. Interfaces 7 (2015) 1608-1615.

[56] Q. Liu, P. Mantilla-Perez, M. Montes Bajo, P. Romero-Gomez, J. Martorell, ACS Appl. Mater. Interfaces 8 (2016) 28750-28756.

[57] J. Reinhardt, M. Grein, C. Buhler, M. Schubert, U. Wurfel, Adv. Energy Mater. 5 (2014)1400081.

[58] M. Vasilopoulou, Nanoscale 6 (2014) 13726-13739.

[59] S. Trost, T. Becker, A. Polywka, P. Görrn, M. F. Oszajca, N. A. Luechinger, D. Rogalla, M. Weidner, P. Reckers, T. Mayer, T. Riedl, Adv. Energy Mater. 6 (2016)1600347.

[60] E. Polydorou, A. Soultati, M. Vasilopoulou, J. Mater. Chem. C. 4 (2016) 691-703.

[61] K. Ellmer, Nature Photonics 6 (2012) 809-817.

[62] L.-Y. Chen, W.-H. Chen, J.-J. Wang, F. Chau-Nan Hong, Appl. Phys. Lett. 85 (2004) 5628-5631.

[63] M. Willander, O. Nur, J. R. Sadaf, M. I. Qadir, S. Zaman, A. Zainelabdin, N. Bano, I. Hussain, Materials 3 (2010) 2643-2667.

[64] V. P. Singh, C. Rath, RSC Adv. 5 (2015) 44390-44397.

[65] E. M. Bachari, G. Baud, S. Ben Amor, Thin Solid Films 348 (1999) 165-172.

[66] M. G. Wardle, J. P. Goss, P. R. Briddon, Phys. Rev. B: Condens. Matter Mater. Phys. 72 (2005) 155108.

[67] B. R. Strohmeier, D. M. Hercules, J. Catal. 86 (1984) 266-279.

[68] O. Lupan, T. Pauporté, L. Chow, B. Viana, F. Pellé, L.K. Ono, B. Roldan Cuenya, H. Heinrich, Appl. Surf. Sci. 256 (2010) 1895-1907.

[69] M. Chen, X. Wang, Y. H Yu, Z. L Pei, X. D Bai, C. Sun, R. F Huang, L. S Wen, Appl. Surf. Sci. 158 (2000) 134-140.

[70] B. K. Stuhl, M. T. Hummon, M. Yeo, G. Quéméner, J. L. Bohn, J. Ye, Nature 492 (2012) 396-401.

[71] P. Cheng, Y. Li, X. Zhan, Energy Environ. Sci. 7 (2014) 2005-2011.

[72] M. Vasilopoulou, L. C. Palilis, D. G. Georgiadou, S. Kennou, I. Kostis, D. Davazoglou, P. Argitis, P. Appl. Phys. Lett. 100 (2012) 013311.

[73] Z. Xu, L.-M. Chen, M.-H. Chen, G. Li, Y. Yang, Appl. Phys. Lett. 95 (2009) 013301.

[74] Q. Bao, X. Liu, Yuxin Xia, Feng Gao, L.-D. Kauffmann, O. Margeat, J. Ackermannc, M. Fahlmana, Mater. Chem. A 2 (2014) 17676

[75] Y.-J. Siao, P.-L. Liu, Y.-T. Wu, Appl. Phys. Expr. 4 (2011) 125601.

[76] J. Briscoe, D. E. Gallardo, S. Hatch, V. Lesnyak, N. Gaponik, S. Dunn, J. Mater. Chem. 21 (2011) 2517-2523.

[77] I. Kostis, N. Vourdas, G. Papadimitropoulos, A. Douvas, M. Vasilopoulou, N. Boukos, D. Davazoglou, J. of Phys. Chem. C 117 (2013) 18013-18020.

[78] H. Li, L. K. Schirrar, J. Shim, H. Cheun, B. Kippelen, O. L. A. Monti, L.-L. Bredas, Chem. Mater. 2012, 24, 3044-3055.

[79] E. H. Kisi, M. M. Elcombe, Acta Crystallogr., Sect. C: Struct. Commun. 45 (1989) 1867-1870. 